Federal Reserve Bank of Minneapolis Research Department

\title{
Asymmetric Expectation Effects of Regime Shifts and the Great Moderation
}

\author{
Zheng Liu, Daniel F. Waggoner, \\ and Tao Zha*
}

Working Paper 653

Revised October 2007

\begin{abstract}
The possibility of regime shifts in monetary policy can have important effects on rational agents' expectation formation and equilibrium dynamics. In a DSGE model where the monetary policy rule switches between a dovish regime that accommodates inflation and a hawkish regime that stabilizes inflation, the expectation effect is asymmetric across regimes. Such an asymmetric effect makes it difficult, but still possible, to generate substantial reductions in the volatilities of inflation and output as the monetary policy switches from the dovish regime to the hawkish regime.
\end{abstract}

*Liu: Emory University and Federal Reserve Bank of Minneapolis, e-mail: zheng.liu@emory.edu; Waggoner: Federal Reserve Bank of Atlanta, e-mail: Daniel.F.Waggoner@atl.frb.org; Zha: Federal Reserve Bank of Atlanta, e-mail: tzha@earthlink.net. We thank Jean Boivin, V. V. Chari, Roger Farmer, Marc Giannoni, Marvin Goodfriend, Nobu Kiyotaki, and especially Michael Golosov and Richard Rogerson for helpful suggestions and discussions. Jean Boivin and Marc Giannoni kindly provided us with their Matlab code for computing MSV solutions. We are grateful to Joan Gieseke for editorial assistance. Liu wishes to thank the Federal Reserve Bank of Minneapolis for their hospitality. The views expressed herein are those of the authors and do not necessarily reflect the views of the Federal Reserve Banks of Atlanta and Minneapolis or the Federal Reserve System. 
[Lucas (1976)] has expressed the view that it makes no sense to think of the government as conducting one of several possible policies while at the same time assuming that agents remain certain about the policy rule in effect.

Cooley, LeRoy, and Raymon (1984, p. 468)

Explicit modelling of the connection of expectation-formation mechanisms to policy [regime] in an accurately identified model would allow better use of the data.

Sims (1982, p. 120)

\section{INTRODUCTION}

In an important strand of literature that studies the macroeconomic effects of changes in monetary policy regime, the prevailing assumption is that private agents form rational expectations with respect to all shocks and underlying uncertainties. At the same time, perhaps paradoxically, it is also assumed that whenever monetary policy enters a particular regime, agents will naively believe that the regime will last forever. For example, the influential work by Clarida, Galí, and Gertler (2000), along with Lubik and Schorfheide (2004) and Boivin and Giannoni (2006), studies macroeconomic effects of two different monetary policy rules, corresponding to the pre-Volcker regime and the post-Volcker regime. By studying the two subsample periods separately, they reach a conclusion that changes in monetary policy help explain the substantial decline in macroeconomic volatility observed in the post-war U.S. economy. The practice of splitting the sample into subsamples reflects the simplifying assumption that after observing a regime shift, agents believe that the current regime will prevail permanently.

Such a simplification does not square well with possible changes in future monetary policy regime. This point has been elaborated by Sims (1982), Sargent (1984), Barro (1984), Cooley, LeRoy, and Raymon (1984), and Sims (1987), among others. These authors argue that in an economy where past changes in monetary policy rules are observable and future changes are likely, rational agents will form a probability distribution over possible policy shifts in the future when forming expectations. ${ }^{1}$ The difference in equilibrium outcomes between a model that ignores probabilistic switches

\footnotetext{
${ }^{1}$ This argument essentially reflects the rational expectations view in that agents form expectations by using all available information, including possible changes in future policy. The rational expectations concept is pioneered by Muth (1961) and Lucas (1972), and advanced by Sargent and Wallace (1975), Barro (1976), and Lucas (1976), among others, in the context of policy evaluations.
} 
in future policy regime and a model that takes into account such expected regime switches reflects the key expectation-formation aspect of the Lucas critique, as implied by the first epigraph. We call this difference the "expectation effect of regime shifts" in monetary policy.

The goal of this paper is twofold. First, we would like to assess the quantitative importance of the expectation effect of regime shifts in monetary policy based on a DSGE model. If the expectation effect turns out to be small, then the equilibrium outcome in a model that rules out future regime changes can be a good approximation to the rational expectations equilibrium. If the expectation effect turns out to be large, however, it will be crucial to assess the equilibrium consequences of expected regime shifts in monetary policy. Second, we would like to examine whether or not, when the expectation effect is accounted for, the model is still capable of predicting the Great Moderation when monetary policy shifts from the dovish regime to the hawkish regime.

Our DSGE model explicitly connects the expectation-formation mechanism to regime shifts in the systematic component of monetary policy, as advocated by Sims (1982). The model features nominal rigidities in the form of staggered price setting and dynamic inflation indexation, and real rigidities in the form of habit formation (e.g., Christiano, Eichenbaum, and Evans 2005, henceforth CEE). Monetary policy follows a Taylor rule, under which the nominal interest rate is adjusted to respond to its own lag and deviations of inflation from its target value and of output from its trend. We generalize the standard DSGE model by allowing coefficients in the monetary policy rule as well as the duration of price contracts and the degree of inflation indexation to change over time. We consider two monetary policy regimes. The first regime represents a policy that responds to inflation weakly (a dovish regime), and the second represents a policy that responds to inflation aggressively (a hawkish regime). Regime changes follow a Markov-switching process, as in Hamilton (1994). We view this kind of regimeswitching structural model as a starting point to study the quantitative importance of expectation effects of regime switching in monetary policy, as emphasized by Sims and Zha (2006) and Cecchetti, et al. (2007). ${ }^{2}$ To isolate the role of policy changes, we keep the shock processes invariant across policy regimes.

\footnotetext{
${ }^{2}$ There has been a growing literature on Markov-switching rational expectations models. See, for example, Andolfatto and Gomme (2003), Leeper and Zha (2003), Schorfheide (2005), Svensson and Williams (2005), Davig and Leeper (2007), and Farmer, Waggoner, and Zha (2007). Following this strand of literature, we generalize the standard DSGE model by allowing the possibility of changes in policy regime to be part of the economic information set. An interesting issue that remains to be addressed is to what extent the probability of a regime shift is affected by the state of the economy
} 
Based on our DSGE model with regime shifts in monetary policy, we obtain the following results:

- The expectation effect of regime change is asymmetric across regimes. Under the dovish policy regime, the volatilities of inflation and output are significantly lower when agents take account of the probability of a switch to the hawkish policy regime than when they naively believe that the dovish regime will persist indefinitely. Under the hawkish policy regime, however, the expectation effect is small. The asymmetric expectation effects arise because equilibrium dynamics are nonlinear functions of the model parameters.

- The importance of the expectation effect depends more on how strong the propagation mechanisms are and less on how persistent the prevailing regime is. The stronger the propagation mechanisms are, the more impact the expectation of future regime change will have on the equilibrium evolution of inflation and output. While in theory the expectation effect disappears if the prevailing regime lasts indefinitely, we find that in practice the expectation effect under the dovish policy regime is quantitatively important even if the regime is very persistent.

- Although expectations of regime switches dampen the fluctuations in inflation and output under the dovish regime, we find that a switch from the dovish regime to the hawkish regime can nonetheless lead to a sizable reduction in the volatility of both inflation and output provided that firms' pricing behavior (characterized by the price-stickiness and inflation-indexation parameters) varies with policy regime.

Understanding the expectation effects of regime shifts helps bridge the gap between two polar approaches in the DSGE literature: one that does not allow for any switch in the systematic component of monetary policy and one that allows for switches in monetary policy regime but does not allow private agents to form expectations about possible changes in future policy. Since the expectation effect under the dovish regime can considerably alter the dynamics of key macroeconomic variables, caution needs to be taken in interpreting empirical models that are used to fit a sample that covers the period with the dovish regime. In the hawkish policy regime, on the other hand, the expectation effect is small even if agents expect that the regime will shift to the dovish regime with a non-trivial probability. Thus, even if a newly instituted hawkish regime investigation. 
is not perfectly credible, such as the Volcker disinflation studied by Goodfriend and King (2005), inflation fluctuations can still be effectively stabilized. Our results also have important empirical implications. Fitting a regime-switching DSGE model to the data takes into account the potentially important expectation effects of regime shifts. Because it does not require splitting a long sample into short subsamples, one can obtain more precise estimates of the "deep" parameters that do not vary with policy regime.

\section{An Illustrative Example}

To illustrate how the expectation effect can arise and to examine some key properties of the expectation effect, we present in this section a simple model with regime shifts in monetary policy. The model is simple enough for us to obtain closed-form analytical results.

II.1. The simple model. Consider an endowment economy in which a one-period risk-free nominal bond is traded. The representative agent maximizes the utility

$$
\mathrm{E} \sum_{t=0}^{\infty} \beta^{t} \frac{c_{t}^{1-\gamma}}{1-\gamma}
$$

subject to the budget constraint

$$
P_{t} c_{t}+B_{t}=P_{t} y_{t}+R_{t-1} B_{t-1}
$$

where $c_{t}$ denotes consumption, $y_{t}$ denotes the endowment, $P_{t}$ denotes the price level, $B_{t}$ denotes the agent's holdings of the bond, and $R_{t-1}$ denotes the nominal interest rate between period $t-1$ and $t$. The parameter $\beta \in(0,1)$ is a subjective discount factor and the parameter $\gamma>0$ measures the relative risk aversion. The endowment follows the exogenous stochastic process

$$
y_{t}=y_{t-1} \lambda \exp \left(z_{t}\right), \quad z_{t}=\rho z_{t-1}+\varepsilon_{t}
$$

where $\lambda \geq 1$ measures the average growth rate of the endowment, $\rho \in(0,1)$ measures the persistence of the endowment shock, and $\varepsilon_{t}$ is an i.i.d. normal process with mean zero and variance $\sigma_{z}^{2}$.

The first order condition with respect to the bond holdings is given by

$$
\frac{c_{t}^{-\gamma}}{P_{t}}=\beta \mathrm{E}_{t} \frac{c_{t+1}^{-\gamma}}{P_{t+1}} R_{t},
$$

which describes the trade-off between spending a dollar today for current consumption and saving a dollar for future consumption. 
Monetary policy follows the interest rate rule

$$
R_{t}=\kappa\left(\frac{\pi_{t}}{\pi^{*}}\right)^{\phi_{s_{t}}}
$$

where $\pi_{t}=P_{t} / P_{t-1}$ is the inflation rate, $\pi^{*}$ denotes the inflation target, $s_{t}$ denotes the realization of monetary policy regime in period $t, \phi_{s_{t}}$ is a regime-dependent parameter that measures the aggressiveness of monetary policy against deviations of inflation from its target, and $\kappa$ is a constant. Monetary policy regime follows a Markov-switching process between two states: a dovish regime characterized by $s_{t}=1$ and $0 \leq \phi_{1}<1$ and a hawkish regime by $s_{t}=2$ and $\phi_{2}>1$. The transition probability matrix $Q=\left[q_{i j}\right]$ is a $2 \times 2$ matrix with $q_{i j}=\operatorname{Prob}\left(s_{t+1}=i \mid s_{t}=j\right)$. Each column of $Q$ sums up to 1 so that $q_{21}=1-q_{11}$ and $q_{12}=1-q_{22}$.

Market clearing implies that $c_{t}=y_{t}$ and $B_{t}=0$ for all $t$. Using the goods market clearing condition, we can rewrite the intertemporal Euler equation as

$$
\beta \mathrm{E}_{t}\left(\frac{y_{t+1}}{y_{t}}\right)^{-\gamma} \frac{R_{t}}{\pi_{t+1}}=1 .
$$

Thus, higher consumption (or income) growth requires a higher real interest rate.

II.2. Steady state and equilibrium dynamics. Given the stochastic process (1) for the endowment, an equilibrium in this economy is summarized by the Euler equation (4) and the monetary policy rule (3). The variables of interest include the inflation rate $\pi_{t}$ and the nominal interest rate $R_{t}$.

A steady state is an equilibrium in which all shocks are shut off (i.e., $\varepsilon_{t}=0$ for all $t$ ). The Euler equation implies that, in the steady state, we have

$$
\frac{R}{\pi}=\frac{\lambda^{\gamma}}{\beta}
$$

Let $\kappa=\frac{\lambda^{\gamma}}{\beta} \pi^{*}$. It follows from the Euler equation (4) and the interest rate rule (3) that the steady-state solution is

$$
\pi=\pi^{*}, \quad R=\frac{\lambda^{\gamma}}{\beta} \pi^{*}
$$

Although monetary policy switches between the two regimes, the steady-state solution does not depend on policy regime and thus allows us to log-linearize the equilibrium conditions around the constant steady state.

Log-linearizing the Euler equation (4) around the steady state results in

$$
\hat{R}_{t}=\mathrm{E}_{t} \hat{\pi}_{t+1}+\gamma \rho z_{t}
$$

where $\hat{R}_{t}$ and $\hat{\pi}_{t}$ denote the log-deviations of the nominal interest rate and the inflation rate from steady state. Equation (5) implies that, following a positive shock to $z_{t}$, the 
real interest rate will rise. This result reflects that an increase in $z_{t}$ leads to a rise in expected consumption growth and thus a rise in the real interest rate. Log-linearizing the interest rate rule (3) around the steady state leads to

$$
\hat{R}_{t}=\phi_{s t} \hat{\pi}_{t}
$$

Combining (5) and (6), we obtain the single equation that describes inflation dynamics:

$$
\phi_{s t} \hat{\pi}_{t}=\mathrm{E}_{t} \hat{\pi}_{t+1}+\gamma \rho z_{t}, \quad s_{t} \in\{1,2\} .
$$

II.3. The MSV solution. We now discuss our approach to solving the model (7) for equilibrium dynamics of inflation. Throughout this paper we follow Boivin and Giannoni (2006) by focusing on the minimum-state-variable (MSV) solution advocated by McCallum (1983).

The state variable in the simple model $(7)$ is the shock $z_{t}$. Thus the solution takes the form $\pi_{t}=\alpha_{s_{t}} z_{t}$, where $\alpha_{s_{t}}$ is to be solved for $s_{t} \in\{1,2\}$. The following proposition gives the analytical solution.

Proposition 1. The MSV solution to the regime-switching model (7) is given by

$$
\hat{\pi}_{t}=\alpha_{s_{t}} z_{t}, \quad s_{t} \in\{1,2\},
$$

where

$$
\left[\begin{array}{l}
\alpha_{1} \\
\alpha_{2}
\end{array}\right]=\left[\begin{array}{cc}
\phi_{1}-\rho q_{11} & -\rho q_{21} \\
-\rho q_{12} & \phi_{2}-\rho q_{22}
\end{array}\right]^{-1}\left[\begin{array}{c}
\gamma \rho \\
\gamma \rho
\end{array}\right],
$$

with the implicit assumption that the matrix above is invertible.

Proof. See Appendix A.1.

The solution represented by (8) implies that the standard deviation of inflation is given by

$$
\sigma_{\pi, 1}=\frac{\left|\alpha_{1}\right|}{\sqrt{1-\rho^{2}}} \sigma_{z}, \quad \sigma_{\pi, 2}=\frac{\left|\alpha_{2}\right|}{\sqrt{1-\rho^{2}}} \sigma_{z} .
$$

The following proposition establishes that the volatility of inflation in the dovish regime decreases with the probability of switching to the hawkish regime and that the volatility of inflation in the hawkish regime increases with the probability of switching to the dovish regime. Thus, the expectation of regime switch affects inflation dynamics.

Proposition 2. Assume that the matrix

$$
A=\left[\begin{array}{cc}
\phi_{1}-\rho q_{11} & -\rho q_{21} \\
-\rho q_{12} & \phi_{2}-\rho q_{22}
\end{array}\right]
$$


is positive definite. Then the MSV solution given by (8) has the property that $\alpha_{j}>0$ for $j \in\{1,2\}$ and that

$$
\frac{\partial \alpha_{1}}{\partial q_{21}}<0, \quad \frac{\partial \alpha_{2}}{\partial q_{12}}>0
$$

Proof. See Appendix A.2.

II.4. Expectation effects. The solution (8) takes into account possible switches of future policy regime. This solution in general differs from that obtained under the simplifying assumption that agents believe that the current regime will continue permanently. The difference between these two solutions is what we call the expectation effect of regime switching.

To examine the underlying forces that drive the expectation effect, we consider the solution that rules out regime shifts in future policy, which is equivalent to solving the following model

$$
\phi_{j} \hat{\pi}_{t}=\mathrm{E}_{t} \hat{\pi}_{t+1}+\gamma \rho z_{t},
$$

where $\phi_{j}(j=1,2)$ does not depend on time. The equilibrium condition (10) is a special case of the condition (7) with $q_{11}=1$ for $j=1$ and with $q_{22}=1$ for $j=2$. The solution to (10) is given by the following proposition.

Proposition 3. The MSV solution to the model described in (10) is

$$
\hat{\pi}_{t}=\bar{\alpha}_{j} z_{t}, \quad \bar{\alpha}_{j}=\frac{\gamma \rho}{\phi_{j}-\rho}, \quad j \in\{1,2\},
$$

where it is assumed that $\phi_{j} \neq \rho$.

Proof. See Appendix A.3.

The solution represented by (11) implies that the standard deviation of inflation under the assumption that rules out changes in future policy regime is given by

$$
\bar{\sigma}_{\pi, 1}=\frac{\left|\bar{\alpha}_{1}\right|}{\sqrt{1-\rho^{2}}} \sigma_{z}, \quad \bar{\sigma}_{\pi, 2}=\frac{\left|\bar{\alpha}_{2}\right|}{\sqrt{1-\rho^{2}}} \sigma_{z} .
$$

The expectation effect of regime switches can be measured by the magnitude $\left|\alpha_{j}-\bar{\alpha}_{j}\right|$ for $j=1,2$. Because $\bar{\alpha}_{j}$ does not depend on transition probabilities, Proposition 2 implies that the less persistent the regime $j$ is, the more significant the expectation effect $\left|\alpha_{j}-\bar{\alpha}_{j}\right|$ becomes. Similarly, it follows from the solutions (8) and (11) that if the endowment growth follows an i.i.d. process $(\rho=0)$, we have $\alpha_{j}=\bar{\alpha}_{j}=0$ for $j \in\{1,2\}$. In other words, if the shock has no persistence, inflation will be completely stabilized regardless of monetary policy regime. There is no expectation effect of regime shifts. If 
the shock is persistent, the solutions (8) and (11) will be different, and the expectation effect will exist.

II.5. Asymmetry. As one can see from (8), $\alpha_{j}$ is the nonlinear function of the model parameters. This nonlinearity implies that when the probabilities of switching are the same for both regimes (i.e., when $q_{11}=q_{22}$ ), the expectation effect may not be symmetric across the two regimes. This result is formally stated in the following proposition.

Proposition 4. Assume that $q_{11}=q_{22}$. If $\phi_{1}>\rho$, then

$$
\frac{\left|\alpha_{1}-\bar{\alpha}_{1}\right|}{\left|\alpha_{2}-\bar{\alpha}_{2}\right|}=\frac{\phi_{2}-\rho}{\phi_{1}-\rho}>1 \text {. }
$$

Proof. See Appendix A.4.

In the dovish regime, as we show in Proposition 2, the expectation of switching to the hawkish regime stabilizes inflation fluctuations; in the hawkish regime, the expectation of switching to the dovish regime destabilizes inflation. Proposition 4 establishes that the stabilizing effect in the dovish regime exceeds the destabilizing effect in the hawkish regime. ${ }^{3}$ Moreover, the expectation effect becomes more asymmetric if the shock is more persistent, if monetary policy takes a stronger hawkish stance against inflation in the hawkish regime, or if policy is less responsive to inflation in the dovish regime.

\section{The DSGE MODEL}

The theoretical results obtained in the previous section provide insight into why the expectation effect exists and how it can be asymmetric across regimes. But how important is the expectation effect of regime shifts? How does the expectation effect change equilibrium dynamics when monetary policy shifts from the dovish regime to the hawkish regime? We address these issues in the context of a dynamic stochastic general equilibrium (DSGE) model of the kind that has become a workhorse for quantitative monetary analysis. ${ }^{4}$

The model economy is populated by a continuum of households, each endowed with a unit of differentiated labor skill indexed by $i \in[0,1]$; and a continuum of firms,

\footnotetext{
${ }^{3}$ In this simple model, it turns out that the percentage changes in the standard deviation of inflation are equal across the two regimes. In a more general setup such as our baseline DSGE model below, the expectation effect is asymmetric across regimes both in terms of levels (as stated in Proposition 4) and in terms of percentage changes.

${ }^{4}$ See, for example, Galí and Gertler (1999), Chari, Kehoe, and McGrattan (2000), Ireland (2004), Lubik and Schorfheide (2004), CEE (2005), Boivin and Giannoni (2006), and Del Negro, et al. (2007).
} 
each producing a differentiated good indexed by $j \in[0,1]$. Households consume a composite of differentiated goods. Firms use a composite of differentiated labor skills as an production input. The composites of goods and labor skills are produced in a perfectly competitive aggregation sector. The monetary authority follows an interest rate rule, in which the policy parameters depend on the realization of a particular policy regime. The policy regime $s_{t}$ follows the same Markov-switching process as described in Section II.1.

III.1. The aggregation sector. The aggregation sector produces a composite labor skill denoted by $L_{t}$ to be used in the production of each type of intermediate goods and a composite final good denoted by $Y_{t}$ to be consumed by each household. The production of the composite skill requires a continuum of differentiated labor skills $\left\{L_{t}(i)\right\}_{i \in[0,1]}$ as inputs, and the production of the composite final good requires a continuum of differentiated intermediate goods $\left\{Y_{t}(j)\right\}_{j \in[0,1]}$ as inputs. The aggregate technologies are given by

$$
L_{t}=\left[\int_{0}^{1} L_{t}(i)^{\frac{\theta_{w t}-1}{\theta_{w t}}} d i\right]^{\frac{\theta_{w t}}{\theta_{w t}-1}}, \quad Y_{t}=\left[\int_{0}^{1} Y_{t}(j)^{\frac{\theta_{p}-1}{\theta_{p}}} d j\right]^{\frac{\theta_{p}}{\theta_{p}-1}},
$$

where $\theta_{w t} \in(1, \infty)$ and $\theta_{p} \in(1, \infty)$ are the elasticity of substitution between the skills and between the goods, respectively. We allow the elasticity of substitution between differentiated skills to be time-varying to capture inefficient labor market wedges, as we will explain further below.

Firms in the aggregation sector face perfectly competitive markets for the composite skill and the composite good. The demand functions for labor skill $i$ and for good $j$ resulting from the optimizing behavior in the aggregation sector are given by

$$
L_{t}^{d}(i)=\left[\frac{W_{t}(i)}{\bar{W}_{t}}\right]^{-\theta_{w t}} L_{t}, \quad Y_{t}^{d}(j)=\left[\frac{P_{t}(j)}{\bar{P}_{t}}\right]^{-\theta_{p}} Y_{t}
$$

where the wage rate $\bar{W}_{t}$ of the composite skill is related to the wage rates $\left\{W_{t}(i)\right\}_{i \in[0,1]}$ of the differentiated skills by $\bar{W}_{t}=\left[\int_{0}^{1} W_{t}(i)^{1-\theta_{w t}} d i\right]^{1 /\left(1-\theta_{w t}\right)}$ and the price $\bar{P}_{t}$ of the composite good is related to the prices $\left\{P_{t}(j)\right\}_{j \in[0,1]}$ of the differentiated goods by $\bar{P}_{t}=\left[\int_{0}^{1} P_{t}(j)^{1-\theta_{p}} d j\right]^{1 /\left(1-\theta_{p}\right)}$.

III.2. The intermediate good sector. The production of a type $j$ good requires labor as the only input with the production function

$$
Y_{t}(j)=Z_{t} L_{t}(j)^{\alpha}, \quad 0<\alpha \leq 1
$$


where $L_{t}(j)$ is the input of the composite skill used by the producer of intermediate good $j$ and $Z_{t}$ is an exogenous productivity shock identical across intermediate-good producers and follows the stochastic process

$$
Z_{t}=Z_{t-1} \lambda \nu_{t}
$$

where $\lambda$ measures the deterministic trend of $Z_{t}$ and $\nu_{t}$ is a stochastic component of $Z_{t}$. The stochastic component follows the stationary process

$$
\log \nu_{t}=\rho_{\nu} \log \nu_{t-1}+\varepsilon_{\nu t}
$$

where $\rho_{\nu} \in(0,1)$ and $\varepsilon_{\nu t}$ is an i.i.d. white noise with mean zero and variance $\sigma_{\nu}^{2}$.

Each firm in the intermediate-good sector is a price-taker in the input market and a monopolistic competitor in the product market where it can set a price for its product, taking the demand schedule in (14) as given. We follow Calvo (1983) and assume that pricing decisions are staggered across firms. We generalize the standard Calvo framework in two dimensions. First, we allow the frequency of price adjustments to depend on monetary policy regime. In particular, we assume that the probability that a firm cannot adjust its price is given by $\eta_{t} \equiv \eta\left(s_{t}\right)$. Under this specification, $\eta_{t}$ is a random variable that follows the same stationary Markov process as does the monetary policy regime. A special case with $\eta_{t}=\eta$ for all $t$ corresponds to the standard model with the Calvo (1983) price-setting. Second, following Woodford (2003) and CEE (2005), we allow a fraction of firms that cannot re-optimize their pricing decisions to index their prices to the overall price inflation realized in the past period. Unlike Woodford (2003) and others, however, we assume that the fraction of indexation varies with the monetary policy regime. Specifically, if the firm $j$ cannot set a new price, its price is automatically updated according to

$$
P_{t}(j)=\pi_{t-1}^{\gamma_{t-1}} \pi^{1-\gamma_{t-1}} P_{t-1}(j),
$$

where $\pi_{t}=\bar{P}_{t} / \bar{P}_{t-1}$ is the inflation rate between $t-1$ and $t, \pi$ is the steady-state inflation rate, and $\gamma_{t} \equiv \gamma\left(s_{t}\right)$ measures the regime-dependent degree of indexation. We view these extensions of the Calvo (1983) framework essential to study the effects of potential changes in monetary policy regime, especially in light of the Lucas (1976) critique. $^{5}$

\footnotetext{
${ }^{5}$ The standard Calvo model with a constant fraction of re-optimizing firms is, in our view, not suitable for studying the effects of potentially large shifts in monetary policy regime. Our concern is not so much about the time-dependent nature of price setting in the Calvo model. Indeed, some studies show that in an environment with low and stable inflation, the main implications of the Calvo model can be well approximated by a model with the state-dependent price setting, since most
} 
Under this generalized Calvo (1983) framework, a firm that can renew its price contract chooses $P_{t}(j)$ to maximize its expected discounted dividend flows given by

$$
\mathrm{E}_{t} \sum_{i=0}^{\infty} \prod_{k=1}^{i} \eta_{t+k-1} D_{t, t+i}\left[P_{t}(j) \chi_{t, t+i} Y_{t+i}^{d}(j)-V_{t+i}(j)\right],
$$

where $D_{t, t+i}$ is the period- $t$ present value of a dollar in a future state in period $t+i$, and $V_{t+i}(j)$ is the cost of production. The term $\chi_{t, t+i}$ comes from the price-updating rule (18) and is given by

$$
\chi_{t, t+i}= \begin{cases}\pi_{t+i-1}^{\gamma_{t+i-1}} \pi_{t+i-2}^{\gamma_{t+i-2}} \cdots \pi_{t}^{\gamma_{t}} \pi^{\Pi_{k=0}^{i-1}\left(1-\gamma_{t+k}\right)} & \text { if } i \geq 1 \\ 1 & \text { if } i=0 .\end{cases}
$$

In maximizing its profit, the firm takes as given the demand schedule $Y_{t+i}^{d}(j)=$ $\left(\frac{P_{t}(j) \chi_{t, t+i}}{\bar{P}_{t+i}}\right)^{-\theta_{p}} Y_{t+i}$.

Solving this profit-maximization problem yields the optimal pricing decision rule

$$
P_{t}(j)=\frac{\theta_{p}}{\theta_{p}-1} \frac{\mathrm{E}_{t} \sum_{i=0}^{\infty} \prod_{k=1}^{i} \eta_{t+k-1} D_{t, t+i} Y_{t+i}^{d}(j) \Phi_{t+i}(j)}{\mathrm{E}_{t} \sum_{i=0}^{\infty} \prod_{k=1}^{i} \eta_{t+k-1} D_{t, t+i} \chi_{t, t+i} Y_{t+i}^{d}(j)},
$$

where $\Phi_{t+i}(j)$ denotes the nominal marginal cost of production, which can be obtained by solving the firm's cost-minimizing problem. Given the production function (15), the marginal cost function facing firm $j$ is given by

$$
\Phi_{t+i}(j)=\frac{1}{\alpha} \frac{W_{t+i}}{Z_{t+i}}\left(\frac{Y_{t+i}(j)^{d}}{Z_{t+i}}\right)^{1 / \alpha-1} .
$$

According to the optimal price-setting equation (21), the optimal price is a markup over an average of the marginal costs for the periods in which the price will remain effective. Clearly, if $\eta_{t}=0$ for all $t$ (that is, if prices are perfectly flexible in all periods), then the optimal price would be a constant markup over the contemporaneous marginal cost.

of the price adjustments occur at the intensive margin while the fraction of firms adjusting prices remains relatively stable (e.g., Gertler and Leahy (2006) and Klenow and Kryvtsov (2005)). Such approximations are likely to break down in an environment with highly variable inflation (such as that in the 1970s) or if changes in monetary policy regime are large (such as the change from the pre-Volcker regime to the Volcker-Greenspan-Bernanke regime). In these situations, the fraction of price-adjusting firms is likely to change across different regimes. Allowing the fraction of adjusting firms to depend on the monetary policy regime, an approach that we take here, essentially captures this regime-switching feature without sacrificing the tractability of the standard Calvo model. 
III.3. Households. There is a continuum of households, each endowed with a differentiated labor skill indexed by $i \in[0,1]$. Household $i$ derives utility from consumption, real money balances, and leisure. The utility function is given by

$$
\mathrm{E} \sum_{t=0}^{\infty} \beta^{t} a_{t}\left\{U\left(C_{t}(i)-b C_{t-1}, \frac{M_{t}(i)}{\bar{P}_{t}}\right)-V\left(L_{t}(i)\right)\right\},
$$

where $\beta \in(0,1)$ is a subjective discount factor, $C_{t}(i)$ denotes the household's consumption of the final composite good, $C_{t-1}$ denotes aggregate consumption in the previous period, $M_{t}(i) / \bar{P}_{t}$ is the real money balances, and $L_{t}(i)$ represents hours worked. The parameter $b$ measures the importance of habit formation in the utility function (e.g., Campbell and Cochrane (1999)). The variable $a_{t}$ denotes a preference shock that follows the stationary process

$$
\log a_{t}=\rho_{a} \log a_{t-1}+\varepsilon_{a t},
$$

where $0 \leq \rho_{a}<1$ and $\varepsilon_{a t}$ is an i.i.d. normal process with mean zero and variance $\sigma_{a}^{2}$.

In each period $t$, the household faces the budget constraint

$$
\bar{P}_{t} C_{t}(i)+\mathrm{E}_{t} D_{t, t+1} B_{t+1}(i)+M_{t}(i) \leq W_{t}(i) L_{t}^{d}(i)+B_{t}(i)+M_{t-1}(i)+\Pi_{t}(i)+T_{t}(i),
$$

for all $t \geq 0$. In the budget constraint, $B_{t+1}(i)$ is a nominal state-contingent bond that represents a claim to one dollar in a particular event in period $t+1$, and this claim costs $D_{t, t+1}$ dollars in period $t ; W_{t}(i)$ is the nominal wage for $i$ 's labor skill, $\Pi_{t}(i)$ is the profit share, and $T_{t}(i)$ is a lump-sum transfer from the government.

The household takes prices and all wages but its own as given and chooses $C_{t}(i)$, $B_{t+1}(i), M_{t}(i)$, and $W_{t}(i)$ to maximize (23) subject to (25), the borrowing constraint $B_{t+1} \geq-\underline{B}$ for some large positive number $\underline{B}$, and the labor demand schedule $L_{t}^{d}(i)$ described in (14).

The optimal wage-setting decision implies that

$$
\frac{W_{t}(i)}{\bar{P}_{t}}=\mu_{w t} \frac{V_{l t}(i)}{U_{c t}(i)}
$$

where $V_{l t}(i)$ and $U_{c t}(i)$ denote the marginal utilities of leisure and of consumption, respectively, and $\mu_{w t}=\frac{\theta_{w t}}{\theta_{w t}-1}$ measures the wage markup. Since the wage-setting decisions are synchronized across households, in a symmetric equilibrium all households set an identical nominal wage and make identical consumption-saving decisions as well. Henceforth, we drop the household index $i$.

The wage markup $\mu_{w t}$ follows the stochastic process

$$
\log \mu_{w t}=\left(1-\rho_{w}\right) \log \mu_{w}+\rho_{w} \log \mu_{w, t-1}+\varepsilon_{w t},
$$


with $\rho_{w} \in(0,1)$ and $\varepsilon_{w t}$ being a white noise process with mean zero and variance $\sigma_{w}^{2}$. The wage markup $\mu_{w t}$ can also be interpreted as a time-varying wedge in the optimal labor-supply decision.

The optimal choice of bond holdings leads to the equilibrium relation

$$
D_{t, t+1}=\beta \frac{a_{t+1} U_{c, t+1}}{a_{t} U_{c t}} \frac{\bar{P}_{t}}{\bar{P}_{t+1}}
$$

and the optimal choice of real balances implies that

$$
\frac{U_{m t}}{U_{c t}}=1-\frac{1}{R_{t}}
$$

where $R_{t}=\left[\mathrm{E}_{t} D_{t, t+1}\right]^{-1}$ is the nominal risk-free rate.

III.4. Monetary policy. Monetary policy is described by an interest rate rule that allows for the possibility of regime switching. The interest rate rule is given by

$$
R_{t}=\kappa\left(s_{t}\right) R_{t-1}^{\rho_{r}\left(s_{t}\right)}\left[\left(\frac{\pi_{t}}{\pi^{*}}\right)^{\phi_{\pi}\left(s_{t}\right)} \tilde{Y}_{t}^{\phi_{y}\left(s_{t}\right)}\right]^{1-\rho_{r}\left(s_{t}\right)} e^{\varepsilon_{r t}},
$$

where $\tilde{Y}_{t}=Y_{t} / Z_{t}$ is detrended output, $\pi^{*}$ is the target rate of inflation, and the policy parameters $\kappa\left(s_{t}\right), \rho_{r}\left(s_{t}\right), \phi_{\pi}\left(s_{t}\right)$, and $\phi_{y}\left(s_{t}\right)$ are regime dependent. The term $\varepsilon_{r t}$ is a shock to monetary policy and follows an i.i.d. normal process with mean zero and variance $\sigma_{r}^{2}$. The state $s_{t}$ represents monetary policy regime and its stochastic process is given in Section II.1. We assume that the shocks $\varepsilon_{r t}, \varepsilon_{a t}, \varepsilon_{w t}$, and $\varepsilon_{\nu t}$ are mutually independent.

Given monetary policy, an equilibrium in this economy consists of prices and allocations such that (i) taking prices and all nominal wages but its own as given, each household's allocation and nominal wage solve its utility maximization problem; (ii) taking wages and all prices but its own as given, each firm's allocation and price solve its profit maximization problem; (iii) markets clear for bond, money balances, composite labor, and composite final goods.

\section{Equilibrium Dynamics}

We now describe the equilibrium dynamics. Because the productivity shock $Z_{t}$ in the model contains a trend, we focus on a stationary equilibrium (i.e., the balanced growth path). To be consistent with balanced growth, we assume that the utility functions 
take the forms

$$
\begin{aligned}
U\left(C_{t}(i)-b C_{t-1}, \frac{M_{t}(i)}{\bar{P}_{t}}\right) & =\log \left(C_{t}(i)-b C_{t-1}\right)+\chi \log \left(\frac{M_{t}(i)}{\bar{P}_{t}}\right), \\
V\left(L_{t}(i)\right) & =\frac{\Psi}{1+\xi} L_{t}(i)^{1+\xi} .
\end{aligned}
$$

We make appropriate transformations of the relevant variables to induce stationarity. The variables to be transformed include aggregate output, consumption, real money balances, and the real wage. In equilibrium, all these variables grow at the same rate as does the productivity shock, so we divide each of these variables by $Z_{t}$ and denote the resulting stationary counterpart of the variable $X_{t}$ by $\tilde{X}_{t}=X_{t} / Z_{t}$.

IV.1. The steady state. We now describe the steady-state equilibrium, where all shocks are turned off. The steady-state equilibrium can be summarized by the solution to the four equilibrium conditions: the optimal pricing decision (21), the optimal wagesetting decision (26), the intertemporal Euler equation (28), and the Taylor rule (30). Once consumption and the nominal interest rate are solved from these equilibrium conditions, we can obtain the real money balances from (29).

The optimal pricing equation (21) implies that in a steady state, the real marginal cost is equal to the inverse of the markup:

$$
\frac{1}{\mu_{p}}=\frac{1}{\alpha} \tilde{W} \tilde{Y}^{1 / \alpha-1}
$$

where $\tilde{W}=\frac{W}{P Z}$ denotes the transformed real wage and $\tilde{Y}=\frac{Y}{Z}$ denotes transformed output.

The wage-setting decision (26) implies that the real wage in the steady state is given by a constant markup over the marginal rate of substitution (MRS):

$$
\tilde{W}=\mu_{w} \Psi L^{\xi}\left(\tilde{Y}-\frac{b}{\lambda} \tilde{C}\right),
$$

where we have used the market clearing condition that aggregate consumption equals aggregate output in equilibrium.

The household's optimal intertemporal decision (28) implies that in the steady-state equilibrium, we have

$$
\frac{R}{\pi}=\frac{\lambda}{\beta}
$$

The Taylor rule in the steady-state equilibrium implies that

$$
R=\kappa(s)^{1 /\left(1-\rho_{r}(s)\right)}\left(\frac{\pi}{\pi^{*}}\right)^{\phi_{\pi}(s)} \tilde{Y}^{\phi_{y}(s)} .
$$


In the steady-state equilibrium, there is a classical dichotomy. The real variables $\tilde{Y}$ and $\tilde{W}$ are determined by the first two equations (31)-(32), while the nominal variables $\pi$ and $R$ are determined by the other two equations (33)-(34) once the real variables are determined.

Although the monetary policy rule is regime-dependent, the steady state is independent of regimes. To see this result, we set $\kappa(s)=\left[\frac{\lambda}{\beta} \pi^{*} \tilde{Y}^{-\phi_{y}(s)}\right]^{1-\rho(s)}$ where $\tilde{Y}$ can be solved from the "real part" of the equilibrium system (i.e.,(31)-(32)). With $\kappa(s)$ so chosen, we obtain the unique steady-state value for inflation and the nominal interest rate:

$$
\pi=\pi^{*}, \quad R=\frac{\lambda}{\beta} \pi^{*} .
$$

IV.2. Equilibrium dynamics. We now study the log-linearized system of equilibrium conditions around the deterministic steady state described above. We focus on the key equations that characterize the equilibrium dynamics.

The log-linearized optimal pricing equation is given by

$$
\begin{aligned}
\hat{\pi}_{t}- & \gamma\left(s_{t-1}\right) \hat{\pi}_{t-1}=\beta \psi_{1}\left(s_{t}, s_{t-1}\right) \mathrm{E}_{t}\left(\hat{\pi}_{t+1}-\gamma\left(s_{t}\right) \hat{\pi}_{t}\right) \\
& +\psi_{2}\left(s_{t-1}\right)\left[\frac{\xi+1}{\alpha} \tilde{y}_{t}+\frac{b}{\lambda-b}\left(\tilde{y}_{t}-\tilde{y}_{t-1}+\hat{\nu}_{t}\right)\right]+\psi_{2}\left(s_{t-1}\right) \hat{\mu}_{w t},
\end{aligned}
$$

where

$\psi_{1}\left(s_{t}, s_{t-1}\right)=\frac{\bar{\eta}}{\eta\left(s_{t-1}\right)} \frac{1-\eta\left(s_{t-1}\right)}{1-\eta\left(s_{t}\right)}, \quad \psi_{2}\left(s_{t-1}\right)=\frac{(1-\beta \bar{\eta})\left(1-\eta\left(s_{t-1}\right)\right)}{\eta\left(s_{t-1}\right)} \frac{1}{1+\theta_{p}(1-\alpha) / \alpha}$,

$\bar{\eta}$ is the ergodic mean of the random variable $\eta\left(s_{t}\right), \hat{\pi}_{t}$ denotes the inflation rate, $\tilde{y}_{t}$ denotes detrended output, $\hat{\nu}_{t}$ denotes the productivity shock, and $\hat{\mu}_{w t}$ denotes the cost-push shock.

Equation (36) generalizes the standard Phillips curve by introducing partial indexation and, more importantly, regime-dependent frequencies of price adjustments and inflation indexation. In the special case where $\eta_{t}=\bar{\eta}$ and $\gamma_{t}=\gamma$ for all $t$, this equation reduces to the standard Phillips curve relation with partial indexation as in Woodford (2003) and Giannoni and Woodford (2003) (augmented with habit formation). If we further impose that $\gamma=0$ and $b=0$ so that there is no indexation and no habit formation, then (36) collapses to the pure forward-looking Phillips-curve relation with the real marginal cost represented by a deviation of output from its trend. In general, because the frequency of price adjustments (measured by $1-\eta_{t}$ ) and the degree of inflation indexation (measured by $\gamma_{t}$ ) are regime dependent, the Phillips curve relation is no longer linear. The non-linearity poses a challenge for computation of the equilibrium, an issue that we will address in Section VI. 
The log-linearized intertemporal Euler equation is given by

$$
\begin{aligned}
& \mathrm{E}_{t} \tilde{y}_{t+1}-\frac{\lambda+b}{\lambda} \tilde{y}_{t}+\frac{b}{\lambda} \tilde{y}_{t-1}= \\
& \quad\left(1-\frac{b}{\lambda}\right)\left(\hat{R}_{t}-\mathrm{E}_{t} \hat{\pi}_{t+1}\right)+\left(\frac{b}{\lambda}-\rho_{\nu}\right) \hat{\nu}_{t}-\frac{(\lambda-b)\left(1-\rho_{a}\right)}{\lambda} \hat{a}_{t},
\end{aligned}
$$

where $\hat{R}_{t}=\log \left(R_{t} / R\right)$ denotes the nominal interest rate. In the special case with no habit formation (i.e., $b=0$ ), equation (37) collapses to the standard intertemporal Euler equation that relates expected output growth to the real interest rate.

The log-linearized interest rate rule is given by

$$
\hat{R}_{t}=\rho_{r}\left(s_{t}\right) \hat{R}_{t-1}+\left(1-\rho_{r}\left(s_{t}\right)\right)\left[\phi_{\pi}\left(s_{t}\right) \hat{\pi}_{t}+\phi_{y}\left(s_{t}\right) \tilde{y}_{t}\right]+\varepsilon_{r t} .
$$

\section{PARAMETERIZATION}

The parameters in our regime-switching model include "deep" parameters that are invariant to policy regimes and regime-dependent parameters. The deep parameters include $\beta$, the subjective discount factor; $b$, the habit parameter; $\xi$, the inverse Frisch elasticity of labor supply; $\alpha$, the elasticity of output with respect to labor; $\theta_{p}$, the elasticity of substitution between differentiated goods; $\mu_{w}$ and $\rho_{w}$, the mean and the $\operatorname{AR}(1)$ coefficient of the cost-push shock process; $\lambda$, the trend growth rate of productivity; $\rho_{a}$ and $\rho_{\nu}$, the $\operatorname{AR}(1)$ coefficients of the preference shock and of the productivity growth processes; and $\sigma_{r}, \sigma_{a}, \sigma_{w}$, and $\sigma_{\nu}$, the standard deviations of the monetary policy shock, the preference shock, the cost-push shock, and the technology shock. The regime-dependent parameters include policy parameters $\rho_{r}, \phi_{\pi}$, and $\phi_{y}$ and the stickiness and indexation parameters $\eta$ and $\gamma$.

The values of the parameters that we use in this paper are summarized in Table 1. These parameter values correspond to a quarterly model. We set $\lambda=1.005$ so that the average annual growth rate of per capital GDP is $2 \%$. We set $\beta=0.9952$ so that, given the value of $\lambda$, the average annual real interest rate (equal to $\lambda / \beta$ ) is $4 \%$. Following the literature, we set $b=0.75$, which is in the range considered by Boldrin, Christiano, and Fisher (2001). The parameter $\xi$ corresponds to the inverse Frisch elasticity of labor supply, which is small (Pencavel, 1986) according to most micro-studies. We set $\xi=2$, corresponding to a Frisch elasticity of 0.5 . We set $\alpha=0.7$, corresponding to a labor income share of $70 \%$. The parameter $\theta_{p}$ determines the steady-state markup. Some studies suggest that the value-added markup is about 1.05 when factor utilization rates are controlled for; without such a correction, it is higher at about 1.12 (Basu and Fernald, 2002). Other studies suggest an even higher value-added markup of about 1.2 
(with no correction for factor utilization) (Rotemberg and Woodford, 1997). In light of these studies, we set $\theta_{p}=10$ so that the steady-state markup is 1.1. For the parameters governing the shock processes, we set $\rho_{a}=0.9, \rho_{\nu}=0.2, \rho_{w}=0.9, \sigma_{a}=0.25, \sigma_{r}=0.2$, $\sigma_{w}=0.4$, and $\sigma_{\nu}=0.2$.

For the regime-dependent parameters, we consider two monetary policy regimes. The first regime (the dovish regime) corresponds to the Mitchell-Burns policy, which does not take a strong stance against inflation fluctuations. The second regime (the hawkish regime) corresponds to the Volcker-Greenspan-Bernanke regime under which price stability is a primary goal. We set $\rho_{r}=0.55$ for both regimes. The value 0.55 is in line with the estimate obtained by Lubik and Schorfheide (2004) for the pre-Volcker regime. In our thought experiment, we set this value to be the same in both regimes for the purpose of isolating the effects of regime changes in policy's endogenous responses to inflation and output. ${ }^{6}$ As we will show later, structural breaks show up significantly in the equilibrium dynamics of the interest rate even though $\rho_{r}$ is held the same across regimes. Based on the estimates obtained by Clarida, Galí, and Gertler (2000), we set $\phi_{\pi 1}=0.83, \phi_{\pi 2}=2.15$; and $\phi_{y 1}=0.27, \phi_{y 2}=0.93$. These values of policy parameters are consistent with the estimates obtained by Lubik and Schorfheide (2004).

As discussed widely in the literature, the dovish regime tends to be destabilizing the economy and can lead to large fluctuations in inflation and output. In that regime, we assume that firms adjust prices more frequently. For the firms that cannot optimize prices, they are more likely to choose inflation indexation under the dovish regime than under the hawkish regime. Consequently, we set $\eta(1)=0.66$ and $\eta(2)=0.75$, so that price contracts last on average for 3 quarters under the dovish regime and 4 quarters under the hawkish regime; we set $\gamma(1)=1$ and $\gamma(2)=0$, so that there is full indexation under the dovish regime and no indexation under the hawkish regime. These values are reported in Panel $\mathrm{C}$ of Table 1. In Panel B, we consider a different thought experiment in which both $\eta$ and $\gamma$ are fixed across regimes so that only regime changes are in the policy responses to inflation and output.

The literature suggests a wide range of values for $\eta$. The work by Eichenbaum and Fisher (2007) suggests that, in a standard Calvo model with mobile capital, the estimated value of $\eta$ based on the postwar US data can be as high as 0.85 , although a lower value in the neighborhood of 0.66 can be obtained if capital inputs are firm specific. CEE (2005) also obtain an estimate of $\eta=0.66$. The survey by Taylor (1999) suggests a value of $\eta=0.75$, while the study by Bils and Klenow (2004) based on the

\footnotetext{
${ }^{6}$ Our results hold even if $\rho_{r}$ is set to zero.
} 
disaggregate consumer price data suggests more frequent price changes, with half of prices lasting 5.5 months or less. Our parameterized value of $\eta$ lies within the range of these empirical studies. The relatively longer duration of price contracts under the hawkish regime, as we have assumed, is consistent with the finding by Lubik and Schorfheide (2004) that price stickiness has increased in the post-1982 period.

For the parameters in the transition matrix $Q$, we set $q_{11}=0.95$ and $q_{22}=0.95$ (and accordingly, $q_{21}=0.05$ and $q_{12}=0.05$ ). These parameter values imply that both regimes are very persistent. In our quantitative analysis, we experiment with other values of transition probabilities to ensure the robustness of our results.

\section{Solving the Regime-Switching Structural Model}

Our model has two non-standard features that pose a challenge for computation. First, since we consider both the dovish regime and the hawkish regime of monetary policy, our parameterization allows for equilibrium indeterminacy. Second, since we allow some key parameters to vary with the monetary policy regime, the equilibrium system is in general non-linear when the policy regime follows a stochastic Markov switching process. Thus, the standard methods for solving rational expectations models such as those described by Blanchard and Kahn (1980), King and Watson (1998), and Uhlig (1999) do not apply. To solve our regime-switching model, we use the generalized MSV approach developed by Farmer, Waggoner, and Zha (2006), which utilizes the canonical VAR form of Sims (2002).

Since the parameters in the equilibrium system depend on regimes in period $t$ and $t-1$ (in particular, the parameters in the Phillips curve relation (36)), it is useful to define a "composite regime" that includes all possible realizations of regimes in periods $t$ and $t-1$. Denote the composite regime by

$$
\tilde{s}_{t}=\left\{s_{t}, s_{t-1}\right\}=\{(1,1),(1,2),(2,1),(2,2)\}
$$

Accordingly, the transition matrix for the composite regime is given by

$$
\underset{4 \times 4}{\tilde{Q}}=\left[\begin{array}{cccc}
q_{11} & q_{11} & 0 & 0 \\
0 & 0 & q_{12} & q_{12} \\
q_{21} & q_{21} & 0 & 0 \\
0 & 0 & q_{22} & q_{22}
\end{array}\right],
$$

where $q_{i j}$ 's are the elements in the $\underset{2 \times 2}{Q}$ matrix.

We use the following notation: 
- $n=$ number of all variables (including expectation terms) for each regime, as in the Gensys setup

- $m=$ number of fundamental shocks

- $\tilde{h}=$ number of policy regimes

- $h^{*}=$ number of shock regimes

- $n_{1}=$ number of equations in each regime

- $n_{2}=$ number of expectation errors

- $n_{3}=$ number of fixed-point equations

- $\tilde{Q}=\tilde{h} \times \tilde{h}$ matrix of transition matrix, whose elements sum up to 1 in each column

In our model, we have $n=8, m=4, \tilde{h}=4, h^{*}=1, n_{1}=6, n_{2}=2, n_{3}=n_{2}(\tilde{h}-1)=6$.

We can now rewrite the equilibrium conditions described in (36) - (38) and the shock processes (17), (24), and (27) in the compact form

$$
\underset{n_{1} \times n n \times 1}{A_{\tilde{s}_{t}} x_{t}}=\underset{n_{1} \times n n \times 1}{B_{\tilde{s}_{t}} x_{t-1}}+\underset{n_{1} \times m_{m \times 1}}{\Psi} \varepsilon_{t},
$$

where

$$
x_{t}=\left[\hat{\pi}_{t}, \tilde{y}_{t}, \hat{R}_{t}, \hat{a}_{t}, \hat{\mu}_{w t}, \hat{\nu}_{t}, \mathrm{E}_{t} \hat{\pi}_{t+1}, \mathrm{E}_{t} \tilde{y}_{t+1}\right]^{\prime}
$$

is a $8 \times 1$ vector of variables to be solved and

$$
\varepsilon_{t}=\left[\varepsilon_{r t}, \varepsilon_{a t}, \varepsilon_{w t}, \varepsilon_{\nu t}\right]^{\prime}
$$

is a $4 \times 1$ vector of shocks.

The coefficient matrices $A_{\tilde{s}_{t}}$ and $B_{\tilde{s}_{t}}$ in (39) involve parameters that are possibly regime-dependent. To fix the notation, we introduce the following definitions:

$$
\begin{gathered}
\gamma_{1}\left(\tilde{s}_{t}\right)=\gamma\left(s_{t-1}\right), \quad \gamma_{0}\left(\tilde{s}_{t}\right)=\gamma\left(s_{t}\right), \\
\psi_{1}\left(\tilde{s}_{t}\right)=\psi_{1}\left(s_{t}, s_{t-1}\right), \quad \psi_{2}\left(\tilde{s}_{t}\right)=\psi_{2}\left(s_{t-1}\right), \\
\rho_{r}\left(\tilde{s}_{t}\right)=\rho_{r}\left(s_{t}\right), \quad \phi_{\pi}\left(\tilde{s}_{t}\right)=\phi_{\pi}\left(s_{t}\right), \quad \phi_{y}\left(\tilde{s}_{t}\right)=\phi_{y}\left(s_{t}\right),
\end{gathered}
$$

which have the following properties:

$$
\begin{array}{cc}
\gamma_{0}\left(\tilde{s}_{t}=1\right)=\gamma_{0}\left(\tilde{s}_{t}=2\right), & \gamma_{0}\left(\tilde{s}_{t}=3\right)=\gamma_{0}\left(\tilde{s}_{t}=4\right), \\
\gamma_{1}\left(\tilde{s}_{t}=1\right)=\gamma_{1}\left(\tilde{s}_{t}=3\right), & \gamma_{1}\left(\tilde{s}_{t}=2\right)=\gamma_{1}\left(\tilde{s}_{t}=4\right), \\
\psi_{2}\left(\tilde{s}_{t}=1\right)=\psi_{2}\left(\tilde{s}_{t}=3\right), & \psi_{2}\left(\tilde{s}_{t}=2\right)=\psi_{2}\left(\tilde{s}_{t}=4\right), \\
\rho_{r}\left(\tilde{s}_{t}=1\right)=\rho_{r}\left(\tilde{s}_{t}=2\right), & \rho_{r}\left(\tilde{s}_{t}=3\right)=\rho_{r}\left(\tilde{s}_{t}=4\right), \\
\rho_{\pi}\left(\tilde{s}_{t}=1\right)=\rho_{\pi}\left(\tilde{s}_{t}=2\right), & \rho_{\pi}\left(\tilde{s}_{t}=3\right)=\rho_{\pi}\left(\tilde{s}_{t}=4\right), \\
\rho_{y}\left(\tilde{s}_{t}=1\right)=\rho_{y}\left(\tilde{s}_{t}=2\right), & \rho_{y}\left(\tilde{s}_{t}=3\right)=\rho_{y}\left(\tilde{s}_{t}=4\right) .
\end{array}
$$


We now fill in the matrices $A_{\tilde{s}_{t}}, B_{\tilde{s}_{t}}$, and $\Psi$ using the three equilibrium conditions and three shock processes as follows.

$$
\begin{aligned}
& A_{\tilde{s}_{t}}= \\
& {\left[\begin{array}{cccccccc}
-\left[1+\beta \psi_{1}\left(\tilde{s}_{t}\right) \gamma_{0}\left(\tilde{s}_{t}\right)\right] & \psi_{2}\left(\tilde{s}_{t}\right)\left[\frac{1+\xi}{\alpha}+\frac{b}{\lambda-b}\right] & 0 & 0 & \psi_{2}\left(\tilde{s}_{t}\right) & \frac{\psi_{2}\left(\tilde{s}_{t}\right) b}{\lambda-b} & \beta \psi_{1}\left(\tilde{s}_{t}\right) & 0 \\
0 & -\frac{\lambda+b}{\lambda} & -\frac{\lambda-b}{\lambda} & \frac{(\lambda-b)\left(1-\rho_{a}\right)}{\lambda} & 0 & \frac{\rho_{\nu} \lambda-b}{\lambda} & \frac{\lambda-b}{\lambda} & 1 \\
-\left(1-\rho\left(\tilde{s}_{t}\right)\right) \phi_{\pi}\left(\tilde{s}_{t}\right) & -\left(1-\rho\left(\tilde{s}_{t}\right)\right) \phi_{y}\left(\tilde{s}_{t}\right) & 1 & 0 & 0 & 0 & 0 & 0 \\
0 & 0 & 0 & 1 & 0 & 0 & 0 & 0 \\
0 & 0 & 0 & 0 & 1 & 0 & 0 & 0 \\
0 & 0 & 0 & 0 & 0 & 1 & 0 & 0
\end{array}\right],} \\
& B_{\tilde{s}_{t}}=\left[\begin{array}{cccccccc}
-\gamma_{1}\left(\tilde{s}_{t}\right) & \psi_{2}\left(\tilde{s}_{t}\right) \frac{b}{\lambda-b} & 0 & 0 & 0 & 0 & 0 & 0 \\
0 & -\frac{b}{\lambda} & 0 & 0 & 0 & 0 & 0 & 0 \\
0 & 0 & \rho\left(\tilde{s}_{t}\right) & 0 & 0 & 0 & 0 & 0 \\
0 & 0 & 0 & \rho_{a} & 0 & 0 & 0 & 0 \\
0 & 0 & 0 & 0 & \rho_{w} & 0 & 0 & 0 \\
0 & 0 & 0 & 0 & 0 & \rho_{\nu} & 0 & 0
\end{array}\right], \\
& \underset{6 \times 4}{\Psi}=\left[\begin{array}{cccc}
0 & 0 & 0 & 0 \\
0 & 0 & 0 & 0 \\
\sigma_{r} & 0 & 0 & 0 \\
0 & \sigma_{a} & 0 & 0 \\
0 & 0 & \sigma_{w} & 0 \\
0 & 0 & 0 & \sigma_{\nu}
\end{array}\right]
\end{aligned}
$$

Following Farmer, Waggoner, and Zha (2006), we can expand the system under each regime, described above, into an expanded linear system to obtain the MSV solution. Appendix B describes the detail of how to form this expanded system.

\section{Quantitative Analysis}

Since monetary policy regime has switched a number of times through the U.S. history, a regime-switching DSGE model of the type studied in this paper is a natural starting point for quantitative analysis. In this section we use the parameterization discussed in Section V to answer the following questions. How important is the expectation effect of regime switches? What are the key properties of the expectation effect? How does the expectation effect alter the equilibrium dynamics of macroeconomic variables? For this purpose, we compare the equilibrium implications from two versions of our model, one in which agents naively believe that the existing policy regime will 
persist indefinitely and one in which agents take into account probabilistic switches in future policy regime. Within each version of the model we also study two cases, one that has regime shifts in policy only (Panel B in Table 1) and the other that allows the parameters $\eta$ and $\gamma$ that govern firms' pricing behaviors to vary with policy regime (Panel C in Table 1).

VII.1. Asymmetric expectation effects. To gauge the importance of the expectation effect of a shift in policy regime, we compare the dynamic behavior of macroeconomic variables in our regime-switching model with that in the version of the model in which agents naively assume that the current regime would last indefinitely.

We begin by examining the case with regime switches in policy but with constant $\eta$ and $\gamma$ (Panel B in Table 1). Figure 1 displays the impulse responses of inflation, output, the ex ante real interest rate, expected inflation, expected output, and the real marginal cost under the dovish regime. At the top of the graphs, "MP" stands for a monetary policy shock, "Demand" for a preference shock, "Cost-push" for a cost-push shock, and "Tech" for a technology shock. Within each graph, two sets of impulse responses are plotted. One corresponds to the version of the model where agents naively assume that the current regime will last indefinitely (the solid line), and the other corresponds to the baseline version of our model where agents take regime switching into account in forming their expectations (the dashed line). The difference between these two sets of impulse responses captures the expectation effects of regime shifts in policy. As shown in Figure 1, even if agents expect the policy to shift from the dovish regime to the hawkish regime with a modest probability of only $5 \%$, the dynamic responses of all variables (particularly those following a demand shock or a cost-push shock) are substantially dampened. If we allow the dovish regime to be less persistent so that it is more likely to switch to the hawkish regime, the expectation effect of regime switching can be further magnified.

Figure 2 displays the impulse responses in the hawkish regime. Although the expectation of regime switching to the dovish regime make the responses slightly more volatile, the model ignoring such an expectation effect nonetheless approximates the regime-switching model well. This result is consistent with the view that monetary policy is more effective in an environment with a low inflation target (Bernanke and Mishkin, 1997; Mishkin, 2004; Goodfriend and King, 2005).

To measure the quantitative importance of the expectation effect and the magnitude of its asymmetry across regimes, we compute the volatilities of inflation, output, and the nominal interest rate. The volatilities are derived from the solution to our structural 
model, which takes the following reduced form

$$
x_{t}=G_{1, s_{t}} x_{t-1}+G_{2, s_{t}} \epsilon_{t},
$$

where matrices $G_{1, s_{t}}$ and $G_{2, s_{t}}$ are functions of the structural parameters. To derive the unconditional volatility of $x_{t}$ for regime $j(j=1,2)$, we fix $G_{1, s_{t}}=G_{1, j}$ and $G_{2, s_{t}}=G_{2, j}$ for all $t$ in (40) and compute $\Omega_{j}^{\text {tot }}=E x_{t} x_{t}^{\prime}$ as

$$
\operatorname{vec}\left(\Omega_{j}^{\mathrm{tot}}\right)=\left(I-G_{1, j} \otimes G_{1, j}\right)^{-1} \operatorname{vec}\left(G_{2, j} G_{2, j}^{\prime}\right) .
$$

The unconditional volatility of $x_{t}$ in regime $j$ is measured by the square root of the diagonal of $\Omega_{j}^{\text {tot }}$. The first three elements of $x_{t}$ are the variables inflation, output, and the nominal interest rate, and their volatilities thus computed are reported in Table 2.

The strong expectation effect in the dovish regime and the lack of it in the hawkish regime are evident by comparing the results across Panels A and B in Table 2. In the dovish regime, the expectation of a shift to the hawkish regime leads to a large decline in macroeconomic volatility. The table shows that the unconditional volatility falls by $76.5 \%$ (from 3.00 to 0.7 ) for inflation, $72.0 \%$ (from 1.19 to 0.33 ) for output, and $76.4 \%$ (from 2.59 to 0.61 ) for the nominal interest rate. In comparison, in the hawkish regime, the expectation of a shift to the dovish regime has a much smaller effect on macroeconomic volatility. ${ }^{7}$

VII.2. Endogenous propagation. Endogenous propagation mechanisms in our model play an important role in generating the asymmetric expectation effects of regime switches. A stronger propagation mechanism through, for example, a stronger strategic complementarity in price setting gives rise to more persistent dynamics of inflation and output. As we have alluded to in Section II, more persistent dynamics, be it from exogenous shock persistence or from endogenous propagation, tend to generate larger and more asymmetric expectation effects of regime shifts. Thus, if we weaken the strategic complementarity, we should expect that expectation effects of regime shifts become smaller and less asymmetric.

To illustrate this point, we set $\theta_{p}=5$ (corresponding to a steady-state markup of $25 \%$ ) and $\eta=0.33$ (corresponding to an average duration of price contract of one and a half quarters), and we focus on the case with constant private-sector parameters. These new parameter values imply a larger value of $\psi_{2}$ in equation (36) and thus

\footnotetext{
${ }^{7}$ The small expectation effect of regime switches in the hawkish regime holds even when the regime is much less persistent (e.g., when $q_{22}=0.7$ ). On the other hand, the expectation effect in the dovish regime remains very strong if we set $q_{11}=0.98$ and $q_{22}=1.0$, the probabilities that might fit into some researchers' a priori belief.
} 
a weaker strategic complementarity in firms' price-setting decisions in the sense of Chari, Kehoe, and McGrattan (2000), Huang and Liu (2001, 2002), and Dotsey and King (2006). With a weaker strategic complementarity, as shown by these authors, inflation and output dynamics become less persistent.

Figures 3 and 4 display the impulse responses of equilibrium variables under the parameterization with $\theta_{p}=5$ and $\eta=0.33$. Compared to the impulse responses with the baseline parameterization reported in Figures 1 and 2, the expectation effects are much smaller and less asymmetric. These results highlight the importance of endogenous propagation for generating large, asymmetric expectation effects of regime shifts.

VII.3. Changes in firms' pricing behavior. We now examine the case in which both the price-stickiness parameter $\eta$ and the inflation-indexation parameter $\gamma$ vary with policy regime. As we have argued, these parameters are likely to change with policy regime, especially when we consider a potentially large change in policy. Figures 5 and 6 display the impulse responses of macroeconomic variables under the dovish and the hawkish regimes. Similar to the case with constant $\eta$ and $\gamma$, the effects of expecting the policy to switch from the dovish regime to the hawkish regime (captured by the differences between the solid and dashed lines in Figure 5) are substantial, but the effects of expecting the policy to switch from the hawkish regime to the dovish regime (Figure 6) are quite small. In fact, the expectation effect of regime switches in the hawkish regime is smaller in comparison with the result from the model with policy change only (c.f. Figure 1). Thus, the asymmetry of expectation effects is stronger in this case. These results are summarized in Table 3 where, when the expectation effect is accounted for, the volatilities of of inflation, output, and the nominal interest rate are substantially reduced in the dovish regime but have little change in the hawkish regime.

VII.4. The Great Moderation. The results discussed in the previous sections show that expectations about changes in future monetary policy can play an important role in affecting the dynamics of macroeconomic variables. Since these expectation effects can significantly dampen the macroeconomic volatility under the dovish policy regime, the following questions naturally arise. Are there significant differences in macroeconomic volatility across the dovish and hawkish regimes? What role do changes in firms' pricing behavior play when we allow the relevant parameters $\eta$ and $\gamma$ to vary with policy regime? 
These questions are important because the volatility of both inflation and output in the U.S. economy has declined substantially since the 1980s. This kind of reduction in macroeconomic volatility is dubbed the "Great Moderation" (Stock and Watson, 2003)). Although what may have caused the Great Moderation is still open to debate, there is a broad consensus that monetary policy played a large role in achieving lower inflation variability (e.g., Bernanke (2004)). Since output volatility and inflation volatility have moved together in the last thirty years, both in the United States and in other industrial economies (e.g., Blanchard and Simon (2001)), Bernanke (2004) suggests that monetary policy may have also played a nontrivial role in moderating output variability as well.

Figure 7 displays the impulse responses of macroeconomic variables in the model with regime changes in policy only (see Panel B in Table 1). The figure shows that as monetary policy switches from the dovish regime (the solid line) to the hawkish regime (the dashed line), the responses of inflation to each of the three shocks are visibly dampened. To measure how much of the volatility is reduced for each variable, Panel $\mathrm{B}$ in Table 2 shows that when monetary policy switches from the dovish regime to the hawkish regime, the volatility of inflation is substantially lowered from 0.70 to 0.18 (a reduction of about $73.8 \%$ ) and the interest-rate volatility falls by about $51 \%$ from 0.61 to 0.30 . This finding is consistent with the view that monetary policy has played an important role in achieving inflation stability. However, switching from the dovish regime to the hawkish regime does not lead to as much of a reduction in the volatility of output: the output volatility falls by about $32 \%$ from 0.33 to 0.22 .

As we have discussed, changes in monetary policy may affect firms' price-setting behavior. To examine the consequence of allowing firms' behavior to respond to changes in policy regime, we now consider the case in which both the price-stickiness parameters $\eta$ and the inflation-indexation parameter $\gamma$ vary with policy regime (Panel $\mathrm{C}$ in Table 1). Figure 8 reports the impulse responses for this case. Compared to the case with constant $\eta$ and $\gamma$ (Figure 7), allowing firms' behavior to vary with policy regime helps dampen the response of output, in addition to dampening the responses of inflation and the nominal interest rate. Panel B in Table 3 shows that as policy switches from the dovish regime to the hawkish regime, not only inflation and the interest rate become more stable but also the volatility of output is reduced substantially. In particular, the output volatility falls by more than a half from 0.35 to 0.16 . These findings lend support to the view that monetary policy may have played an important role in the Great Moderation. ${ }^{8}$

\footnotetext{
${ }^{8}$ The Great Moderation is stronger when we set $q_{11}=0.98$ and $q_{22}=1.0$.
} 
VII.5. Propagation Effect vs. Magnification Effect. A regime shift in monetary policy affects equilibrium dynamics through two channels: a propagation effect (through the $G_{1 s_{t}}$ matrix in (40)) and a magnification effect (through the $G_{2 s_{t}}$ matrix). To understand the transmission mechanism of regime switches in monetary policy, it is necessary to separate these two effects on the unconditional volatility of macroeconomic variables (Cogley and Sargent, 2005). ${ }^{9}$

In Appendix C, we discuss our approach of separating the propagation effect from the magnification effect of regime changes in monetary policy. Table 4 reports the percentage reductions in the unconditional volatility as well as its decomposition when monetary policy shifts from the dovish regime to the hawkish regime. ${ }^{10}$ The table shows that a shift in policy regime substantially reduces the unconditional volatilities of inflation and the nominal interest rate, regardless of whether or not firms' pricing behavior varies with policy regime (Panel A in Table 4). The bulk of such a volatility reduction is accounted for by the propagation effect (Panels B and $\mathrm{C}$ in Table 4). When the price-stickiness parameter and the indexation parameter are held constant across regimes, a shift of monetary policy from the dovish regime to the hawkish regime leads to a modest reduction in the unconditional volatility of output (about 32\%), with the propagation effect slightly smaller than the magnification effect (15\% v. 19\%). When these private-sector parameters are allowed to vary with policy regime, however, a switch of policy from the dovish regime to the hawkish regime leads to a substantial decline in the unconditional volatility of output (about 53\%) and the propagation effect becomes more important than the magnification effect (37\% v. 24\%).

\section{CONCLUSION}

We have studied a standard DSGE model where monetary policy follows a Markov switching process between two distinct regimes: a dovish regime under which the

\footnotetext{
${ }^{9}$ Since we assume that the variances of fundamental shocks remain constant over time, our thought experiment sidesteps the important question of whether changes in monetary policy or changes in the distribution of shocks have been more important for explaining the Great Moderation. To address that question requires estimating a DSGE model with regime shifts in both policy and shock variances, which is beyond the scope of this paper. For some recent studies on the relative importance of policy versus shocks, see Stock and Watson (2003), Cogley and Sargent (2005), Primiceri (2005), Sims and Zha (2006), and Gambetti, Pappa, and Canova (forthcoming).

${ }^{10}$ The percentage reductions in volatility attributable to the propagation effect and to the magnification effect are not supposed to sum up to the percentage reductions in the unconditional volatility because of the nonlinearity in our decomposition. The relationship is approximately multiplicative, not additive. See Appendix C for details.
} 
policy responds weakly to fluctuations in inflation and a hawkish regime under which the price stability is a top priority. Our study represents a concrete step to fulfill the rational expectations research program outlined by Sims (1982), Sargent (1984), Barro (1984), Cooley, LeRoy, and Raymon (1984), and Sims (1987). We have shown that (1) because macroeconomic dynamics are nonlinear functions of the underlying model parameters, the expectation effect of regime switches in monetary policy is asymmetric across regimes and (2) by allowing firms' pricing behavior to vary with policy regime, the volatility of both inflation and output can be significantly reduced when policy switches out of the dovish regime into the hawkish regime.

Since the expectation effect can be quantitatively important under the dovish policy regime, it should not be ignored in the DSGE model that aims at assessing the impact of a regime change in historical monetary policy. In the hawkish policy regime, on the other hand, the expectation effect of future policy change is quantitatively insignificant. This asymmetric finding offers an explanation of why the post-1980 monetary policy in the United States has been successful in reducing the volatility of both inflation and output, despite agents' disbelief that the hawkish policy will last forever (Goodfriend and King, 2005).

We have also shown that the reduction in macroeconomic volatility can be attributed more to a regime change in the persistence of equilibrium dynamics of the variables than to that in the size of reduced-form shock variances. Therefore, a structural break in the persistence parameters may provide an essential transmission mechanism for reducing macroeconomic volatility. We hope that the quantitative findings obtained in this paper will help motivate researchers to take up a challenging task of estimating a regime-switching DSGE model to a long sample that covers different policy regimes and structural breaks.

\section{Appendix A. Proofs of Propositions}

A.1. Proof of Proposition 1. We solve the model (7) by the method of undetermined coefficients. Given the solution form $\hat{\pi}_{t}=\alpha_{s_{t}} z_{t}$ for $s_{t} \in\{1,2\},(7)$ implies that

$$
\begin{aligned}
\phi_{1} \alpha_{1} z_{t} & =q_{11} \alpha_{1} \rho z_{t}+q_{21} \alpha_{2} \rho z_{t}+\gamma \rho z_{t}, \\
\phi_{2} \alpha_{2} z_{t} & =q_{12} \alpha_{1} \rho z_{t}+q_{22} \alpha_{2} \rho z_{t}+\gamma \rho z_{t},
\end{aligned}
$$

where we have used the relation $\mathrm{E}_{t} z_{t+1}=\rho z_{t}$. Matching the coefficients on $z_{t}$, we obtain

$$
\phi_{1} \alpha_{1}=q_{11} \alpha_{1} \rho+q_{21} \alpha_{2} \rho+\gamma \rho
$$




$$
\phi_{2} \alpha_{2}=q_{12} \alpha_{1} \rho+q_{22} \alpha_{2} \rho+\gamma \rho .
$$

It follows that the solution $\left[\alpha_{1}, \alpha_{2}\right]^{\prime}$ is given by the expression in (8).

A.2. Proof of Proposition 2. Denote by $\alpha=\left[\alpha_{1}, \alpha_{2}\right]^{\prime}$ and $C=\gamma \rho[1,1]^{\prime}$. The MSV solution in (8) can be rewritten as

$$
\alpha=A^{-1} C
$$

Since $A$ is positive definite, $\alpha_{1}$ and $\alpha_{2}$ are both positive.

To establish the first inequality in (9), we impose the relation $q_{11}=1-q_{21}$ and differentiate (A1) and (A2) with respect to $q_{21}$ to obtain

$$
\begin{aligned}
\phi_{1} \frac{\partial \alpha_{1}}{\partial q_{21}} & =q_{11} \rho \frac{\partial \alpha_{1}}{\partial q_{21}}+\left(\alpha_{2}-\alpha_{1}\right) \rho+q_{21} \rho \frac{\partial \alpha_{2}}{\partial q_{21}} \\
\phi_{2} \frac{\partial \alpha_{2}}{\partial q_{21}} & =q_{12} \rho \frac{\partial \alpha_{1}}{\partial q_{21}}+q_{22} \rho \frac{\partial \alpha_{2}}{\partial q_{21}} .
\end{aligned}
$$

With appropriate substitutions, we get

$$
\frac{\partial \alpha_{1}}{\partial q_{21}}=\frac{\gamma \rho^{2}\left(\phi_{2}-q_{22} \rho\right)\left(\phi_{1}-\phi_{2}\right)}{\operatorname{det}(A)^{2}}<0,
$$

where the inequality follows from the assumption that $\phi_{1}<1<\phi_{2}$. Similarly, we can show that

$$
\frac{\partial \alpha_{2}}{\partial q_{12}}=\frac{\gamma \rho^{2}\left(\phi_{1}-q_{11} \rho\right)\left(\phi_{2}-\phi_{1}\right)}{\operatorname{det}(A)^{2}} .
$$

Since $A$ is assumed to be positive definite, we have $\operatorname{det}(A)>0$ so that

$$
\phi_{1}-q_{11} \rho>\frac{q_{21} q_{12} \rho^{2}}{\phi_{2}-q_{22} \rho}>0 .
$$

This inequality, along with the assumption that $\phi_{2}>\phi_{1}$, implies that $\frac{\partial \alpha_{2}}{\partial q_{12}}>0$.

A.3. Proof of Proposition 3. Given the solution form $\hat{\pi}_{t}=\bar{\alpha}_{j} z_{t}$, we have $\mathrm{E}_{t} \hat{\pi}_{t+1}=$ $\bar{\alpha}_{j} \rho z_{t}$ and (11) is a result from matching the coefficients of $z_{t}$.

A.4. Proof of Proposition 4. The solution for the regime-switching model (8) can be rewritten as

$$
\alpha_{j}=\frac{q_{i j} \rho+\phi_{i}-q_{i i} \rho}{\operatorname{det}(A)}, \quad i j \in\{1,2\}, \quad i \neq j
$$


Using the solution for the constant regime model in (11), we have

$$
\begin{aligned}
\frac{\bar{\alpha}_{1}-\alpha_{1}}{\alpha_{2}-\bar{\alpha}_{2}} & =\frac{\frac{1}{\phi_{1}-\rho}-\frac{q_{21} \rho+\phi_{2}-q_{22} \rho}{\operatorname{det}(A)}}{\frac{q_{12} \rho+\phi_{1}-q_{11} \rho}{\operatorname{det}(A)}-\frac{1}{\phi_{2}-\rho}} \\
& =\frac{\phi_{2}-\rho}{\phi_{1}-\rho} \frac{\operatorname{det}(A)-\left(\phi_{1}-\rho\right)\left(q_{21} \rho+\phi_{2}-q_{22} \rho\right)}{\left(\phi_{2}-\rho\right)\left(q_{12} \rho+\phi_{1}-q_{11} \rho\right)-\operatorname{det}(A)} \\
& =\frac{\phi_{2}-\rho}{\phi_{1}-\rho} \frac{1-q_{11}}{1-q_{22}} .
\end{aligned}
$$

The desired inequality in (12) follows from the assumptions that $q_{11}=q_{22}$ and $\phi_{2}>\phi_{1}$.

\section{Appendix B. The Expanded Model}

To solve the model described in (39), we stack all variables under each regime and form an expanded model

$$
\underset{32 \times 32}{A} \underset{32 \times 1}{X_{t}}=\underset{32 \times 32}{B} \underset{32 \times 1}{X_{t-1}}+\underset{32 \times 4848 \times 1}{\Gamma_{u}} \underset{32 \times 2}{u_{t}}+\underset{32 \times 1}{\Gamma_{\eta}} \eta_{t}
$$

where

$$
\begin{aligned}
& \underset{32 \times 1}{X_{t}}=\left[\begin{array}{c}
x_{1, t} \\
8 \times 1 \\
\vdots \\
x_{4, t} \\
8 \times 1
\end{array}\right] \equiv\left[\begin{array}{ccc}
\boldsymbol{\iota}\left\{\tilde{s}_{t}=1\right\} & x_{t} \\
\vdots & \\
8 \times 1 \\
\boldsymbol{\iota}\left\{\tilde{s}_{t}=4\right\} & x_{t} \\
& & 8 \times 1
\end{array}\right], \\
& \underset{32 \times 32}{A}=\left[\begin{array}{c}
\underbrace{\underbrace{\operatorname{diag}\left(A_{1}, \ldots, A_{h}\right)}_{2 \times 32}}_{24 \times 32} \\
\underbrace{6 \text { expectation errors }}_{6 \times 32}
\end{array}\right], \\
& =[\underbrace{\underbrace{\operatorname{diag}\left(A_{1}, \ldots, A_{h}\right)}_{24 \times 32}}
\end{aligned}
$$




$$
\begin{aligned}
& \underset{32 \times 32}{B}=[\underbrace{\underbrace{\operatorname{diag}\left(B_{1}, \ldots, B_{4}\right)\left(\tilde{Q} \otimes \boldsymbol{I}_{8}\right)}_{6 \times 32}}_{2 \times 32} \underbrace{2 \text { expectation errors }}_{\underbrace{}_{6 \times 32}} \\
& =[\underbrace{\left[\begin{array}{cccc}
q_{11} B_{1} & \cdots & q_{14} B_{1} \\
& \vdots & \\
& & & \\
q_{41} B_{4} & \cdots & q_{44} B_{4}
\end{array}\right]}_{\underbrace{\boldsymbol{O}_{6 \times 32}}_{6 \times 32}} \\
& \underset{32 \times 48}{\Gamma_{u}}=\left[\begin{array}{c:c}
\boldsymbol{I}_{24} & \boldsymbol{I}_{24} \\
\boldsymbol{O}_{8 \times 24} & \boldsymbol{O}_{8 \times 24}
\end{array}\right], \underset{48 \times 1}{u_{t}}=\left[\begin{array}{c}
S_{s_{t}} X_{t-1} \\
24 \times 3232 \times 1 \\
\hdashline \mathcal{E}_{t} \\
24 \times 1
\end{array}\right], \\
& \underset{24 \times 32}{S_{s_{t}}}=\left[\begin{array}{ccc}
\left(\iota\left\{\tilde{s}_{t}=1\right\}-\tilde{q}_{11}\right) B_{1} & \ldots & \left(\boldsymbol{\iota}\left\{\tilde{s}_{t}=1\right\}-\tilde{q}_{14}\right) B_{1} \\
\vdots & \vdots & \vdots \\
\left(\iota\left\{\tilde{s}_{t}=4\right\}-\tilde{q}_{41}\right) B_{4} & \ldots & \left(\iota\left\{\tilde{s}_{t}=4\right\}-\tilde{q}_{44}\right) B_{4}
\end{array}\right] \\
& \equiv \operatorname{diag}\left(B_{1}, \cdots, B_{4}\right)\left[\left(\boldsymbol{e}_{\tilde{s}_{t}} \mathbf{1}_{4}^{\prime}-\tilde{Q}\right) \otimes \boldsymbol{I}_{8}\right] \text {, } \\
& \boldsymbol{e}_{s_{t}}=\left[\begin{array}{c}
\boldsymbol{\iota}\left\{\tilde{s}_{t}=1\right\} \\
\vdots \\
\iota\left\{\tilde{s}_{t}=4\right\}
\end{array}\right], \mathbf{1}_{4}=\left[\begin{array}{c}
1 \\
\vdots \\
1
\end{array}\right] \\
& \mathcal{E}_{24 \times 1}=\underbrace{\left[\begin{array}{ccc}
\Psi & & \boldsymbol{O} \\
& \ldots & \\
\boldsymbol{O} & & \Psi
\end{array}\right]}_{24 \times 16} \underbrace{\left[\begin{array}{c}
\boldsymbol{\iota}\left\{\tilde{s}_{t}=1\right\} \varepsilon_{t} \\
\vdots \\
\boldsymbol{\iota}\left\{\tilde{s}_{t}=4\right\} \varepsilon_{t}
\end{array}\right]}_{16 \times 1}, \\
& \underset{32 \times 2}{\Gamma_{\eta}}=\left[\begin{array}{c}
\boldsymbol{O}_{24 \times 2} \\
\boldsymbol{I}_{2} \\
\boldsymbol{O}_{6 \times 2}
\end{array}\right]
\end{aligned}
$$




\section{Appendix C. Propagation v. Magnification}

To separate the propagation effect from the magnification effect of regime changes in monetary policy, let us begin with the simple example

$$
\hat{\pi}_{t}=\rho_{s_{t}} \hat{\pi}_{t-1}+\sigma_{s_{t}} \epsilon_{t}
$$

where $\epsilon_{t}$ is an i.i.d. process with the standard normal distribution. In regime $j(j=$ $1,2)$, the volatility of inflation is measured by

$$
v_{j}=\frac{\sigma_{j}}{\sqrt{1-\rho_{j}^{2}}} .
$$

Thus, a relative change in volatility from the first regime to the second regime can be characterized by

$$
\frac{v_{2}}{v_{1}}=\frac{\sqrt{1-\rho_{1}^{2}}}{\sqrt{1-\rho_{2}^{2}}} \frac{\sigma_{2}}{\sigma_{1}} .
$$

As one can see from (A4), the change in the unconditional volatility can be decomposed into two components, one attributable to regime-induced changes in persistence, which we call the propagation effect (measured by the first term on the right-hand side), and the other attributable to regime-induced changes in shock variances, which we call the magnification effect (measured by the second term on the right-hand side).

We perform a similar analysis for the higher-dimensional process (40). The unconditional volatility of $x_{t}$ for regime $j(j=1,2)$ can be calculated according to (41). When policy shifts from the dovish (first) regime to the hawkish (second) regime, how much of the change in the unconditional volatility can be attributed to the propagation effect and how much to the magnification effect? Because $x_{t}$ is in general multi-dimensional, one cannot obtain an exact decomposition as in the univariate example represented by (A4). One can, however, obtain an approximate decomposition.

We begin by computing the volatility attributable to the magnification effect (measured by the matrix $G_{2, j}$ for regime $j$ ). According to Gallant, Rossi, and Tauchen (1993), the magnification effect in regime $j$ can be characterized by the impulse response matrix at time $t$ defined as

$$
\mathcal{I}_{t, j}=\left(\prod_{k=1}^{t} G_{1, s_{k}}\right) G_{2, j}
$$

where $s_{0}=j$ and $s_{k}(k=1, \ldots, t)$ evolves according to the Markov-switching process. To get the overall variation described by the stochastic processes $\mathcal{I}_{t, j}$ for $t=1, \ldots, \infty$ 
amounts to computing the covariance matrix $\Omega_{j}^{\text {shk }}=E x_{t} x_{t}^{\prime}$ with $G_{2, s_{t}}=G_{2, j}$ for all $t$ in (40). This covariance matrix is

$$
\operatorname{vec}\left(\Omega_{j}^{\text {shk }}\right)=\left(I-\bar{q}_{1} G_{1,1} \otimes G_{1,1}-\bar{q}_{2} G_{1,2} \otimes G_{1,2}\right)^{-1} \operatorname{vec}\left(G_{2, j} G_{2, j}^{\prime}\right),
$$

where $\bar{q}_{j}$ is the ergodic probability for regime $j$. The volatility of $x_{j}$ associated with the shock-covariance matrix $G_{2, j}(j=1,2)$ is measured by the square root of the diagonal of $\Omega_{j}^{\text {shk }}$.

Similarly, to isolate the propagation effect measured by $G_{1, j}$, we compute the covariance matrix $\Omega_{j}^{\text {per }}=E x_{t} x_{t}^{\prime}$ with $G_{1, s_{t}}=G_{1, j}$ for all $t$ in (40) as

$$
\operatorname{vec}\left(\Omega_{j}^{\text {per }}\right)=\left(I-G_{1, j} \otimes G_{1, j}\right)^{-1} \operatorname{vec}\left(\bar{q}_{1} G_{2,1} G_{2,1}^{\prime}+\bar{q}_{2} G_{2,2} G_{2,2}^{\prime}\right) .
$$

The change in volatility due to the propagation effect represented by the matrix $G_{1, j}$ for regime $j$ is given by the square root of the diagonal of $\Omega_{j}^{\text {per }}$.

Upon obtaining the decomposition of the regime-induced changes in volatility, we calculate a percentage reduction in volatility as $100\left(1-v_{2}^{\text {tot }} / v_{1}^{\text {tot }}\right), 100\left(1-v_{2}^{\text {shk }} / v_{1}^{\text {shk }}\right)$, or $100\left(1-v_{2}^{\text {per }} / v_{1}^{\text {per }}\right)$, where $v_{j}^{\text {tot }}$ measures the volatility computed according to $(41), v_{j}^{\text {shk }}$ according to (A5), and $v_{j}^{\text {per }}$ according to (A6). One can verify from Table 4 that the relationship among $v_{2}^{\text {tot }} / v_{1}^{\text {tot }}, v_{2}^{\text {shk }} / v_{1}^{\text {shkt }}$, and $v_{2}^{\text {per }} / v_{1}^{\text {per }}$ is approximately multiplicative, that is,

$$
\frac{v_{2}^{\text {tot }}}{v_{1}^{\text {tot }}} \approx \frac{v_{2}^{\text {shk }}}{v_{1}^{\text {shk }}} \frac{v_{2}^{\text {per }}}{v_{1}^{\text {per }}} .
$$

In the univariate example, this relation is exact, as revealed by (A4). 
TABLE 1. Parameter values

\begin{tabular}{|c|c|c|c|}
\hline \multicolumn{4}{|c|}{ A. "Deep" parameters } \\
\hline Preferences & $\beta=0.9952$ & $\xi=2$ & $b=0.75$ \\
\hline Technologies & $\alpha=0.7$ & $\lambda=1.005$ & $\theta_{p}=10$ \\
\hline \multicolumn{4}{|l|}{ Aggregate Shocks } \\
\hline Persistence & $\rho_{a}=0.9$ & $\rho_{w}=0.9$ & $\rho_{\nu}=0.2$ \\
\hline Standard dev. & $\sigma_{r}=0.2$ & $\sigma_{a}=0.25$ & $\sigma_{w}=0.4 \quad \sigma_{\nu}=0.2$ \\
\hline Regime transition prob. & $q_{11}=0.95$ & $q_{22}=0.95$ & \\
\hline
\end{tabular}

B. Regime-dependent parameters for policy change only

\begin{tabular}{llllll}
\hline Regime & $\rho_{r}$ & $\phi_{\pi}$ & $\phi_{y}$ & $\eta$ & $\gamma$ \\
\hline Dovish regime & 0.55 & 0.83 & 0.27 & 0.66 & 1 \\
Hawkish regime & 0.55 & 2.15 & 0.93 & 0.66 & 1 \\
\hline
\end{tabular}

C. Regime-dependent parameters for changes in both policy and firms

\begin{tabular}{llllll}
\hline Regime & $\rho_{r}$ & $\phi_{\pi}$ & $\phi_{y}$ & $\eta$ & $\gamma$ \\
\hline Dovish regime & 0.55 & 0.83 & 0.27 & 0.66 & 1 \\
Hawkish regime & 0.55 & 2.15 & 0.93 & 0.75 & 0 \\
\hline
\end{tabular}

TABLE 2. Effects of regime shifts in policy on macroeconomic volatility

\begin{tabular}{llll}
\hline \hline & \multicolumn{3}{c}{ A. Ignoring Expectation Effects } \\
\cline { 2 - 4 } & Inflation & Output & Interest rate \\
\hline Dovish regime & 3.00 & 1.19 & 2.59 \\
Hawkish regime & 0.14 & 0.20 & 0.24 \\
\hline & B. Accounting for & Expectation Effects \\
\cline { 2 - 4 } & Inflation & Output & Interest rate \\
\hline Dovish regime & 0.70 & 0.33 & 0.61 \\
Hawkish regime & 0.18 & 0.22 & 0.30 \\
\hline
\end{tabular}


TABLE 3. Effects of regime shifts in both policy and firms' pricing behavior on macroeconomic volatility

\begin{tabular}{llll}
\hline \hline & \multicolumn{3}{c}{ A. Ignoring Expectation Effects } \\
\cline { 2 - 4 } & Inflation & Output & Interest rate \\
\hline Dovish regime & 3.00 & 1.19 & 2.59 \\
Hawkish regime & 0.08 & 0.17 & 0.21 \\
\hline & B. Accounting for & Expectation Effects \\
\cline { 2 - 4 } & Inflation & Output & Interest rate \\
\hline Dovish regime & 0.80 & 0.35 & 0.69 \\
Hawkish regime & 0.09 & 0.16 & 0.23 \\
\hline
\end{tabular}

TABLE 4. Reduction in volatility (\% change) when policy shifts from the dovish regime to the hawkish regime

\begin{tabular}{|c|c|c|c|}
\hline & \multicolumn{3}{|c|}{ A. Unconditional Volatility } \\
\hline & Inflation & Output & Interest rate \\
\hline Policy only & 73.79 & 32.33 & 50.91 \\
\hline \multirow[t]{3}{*}{ Policy and firms } & 88.76 & 53.02 & 66.12 \\
\hline & \multicolumn{3}{|c|}{ B. Propagation Effect } \\
\hline & Inflation & Output & Interest rate \\
\hline Policy only & 67.65 & 15.10 & 42.72 \\
\hline \multirow[t]{3}{*}{ Policy and firms } & 84.78 & 37.41 & 62.72 \\
\hline & \multicolumn{3}{|c|}{ C. Magnification Effect } \\
\hline & Inflation & Output & Interest rate \\
\hline Policy only & 13.02 & 19.15 & 11.27 \\
\hline Policy and firms & 13.19 & 23.94 & 8.81 \\
\hline
\end{tabular}



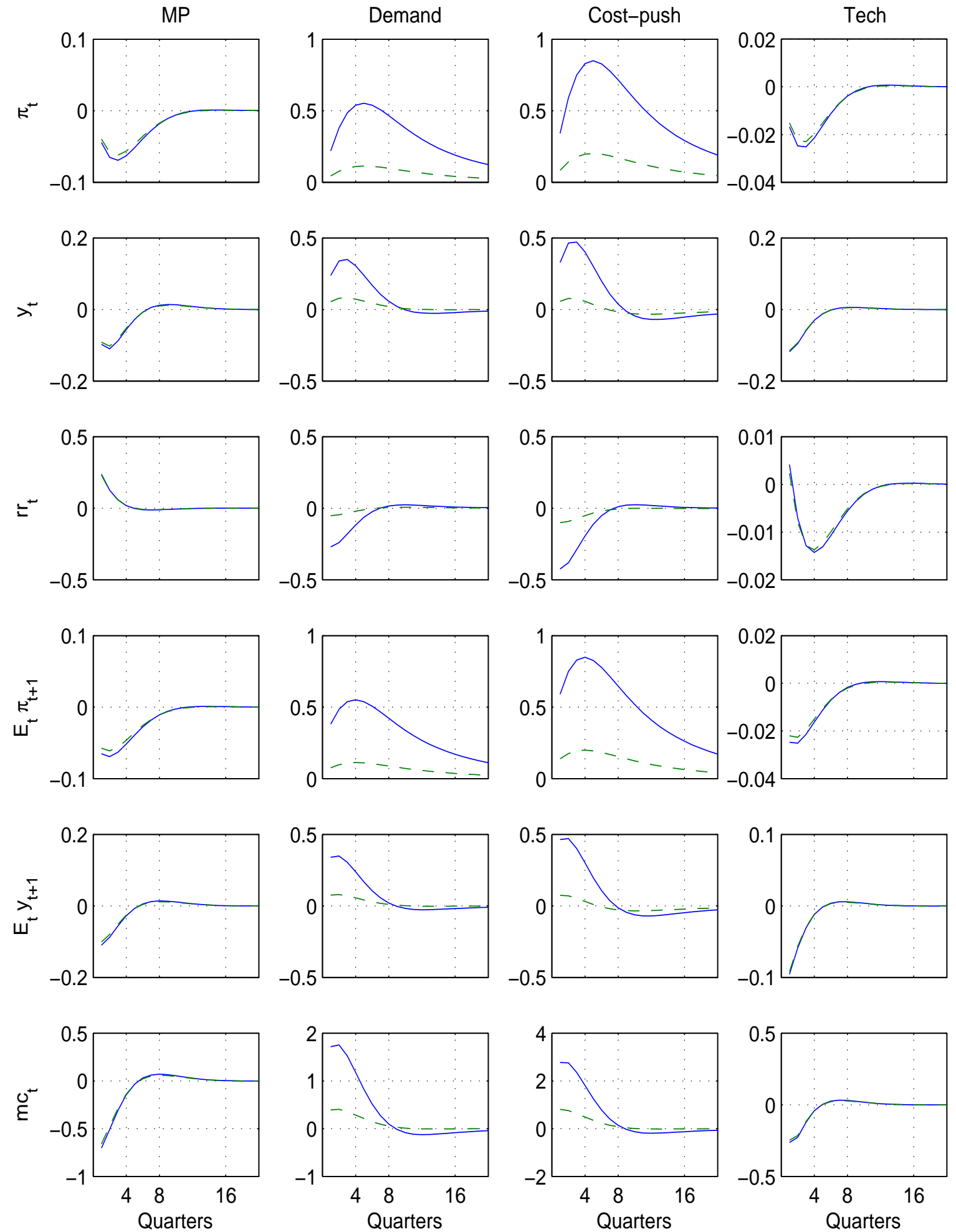

FiguRE 1. Regime switching in policy only: impulse responses under the dovish policy regime. The solid line represents the responses from the model that ignores regime shifts in future policy. The dashed line represents the responses from our regime-switching model. 

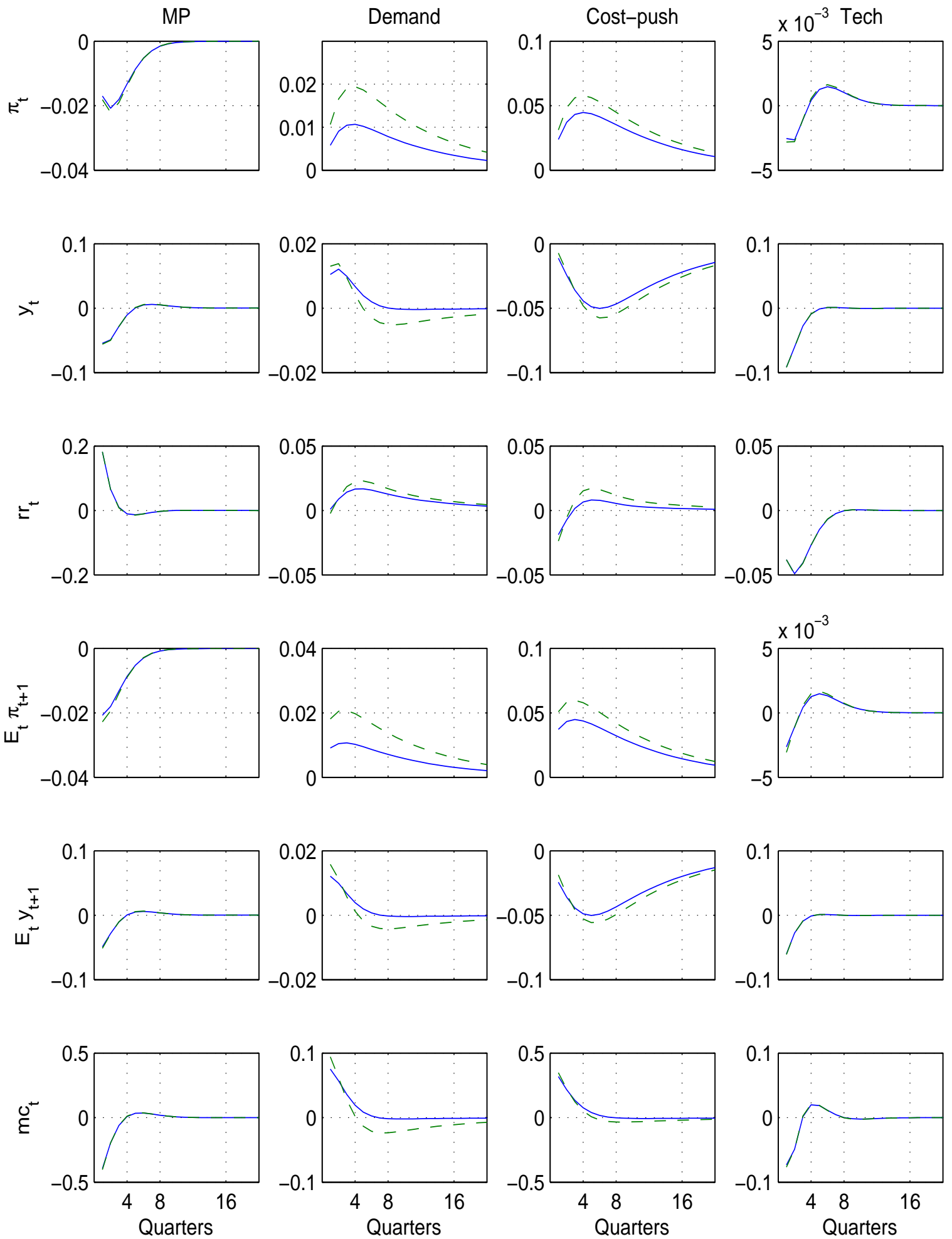

FiguRE 2. Regime switching in policy only: impulse responses under the hawkish policy regime. The solid line represents the responses from the model that ignores regime shifts in future policy. The dashed line represents the responses from our regime-switching model. 

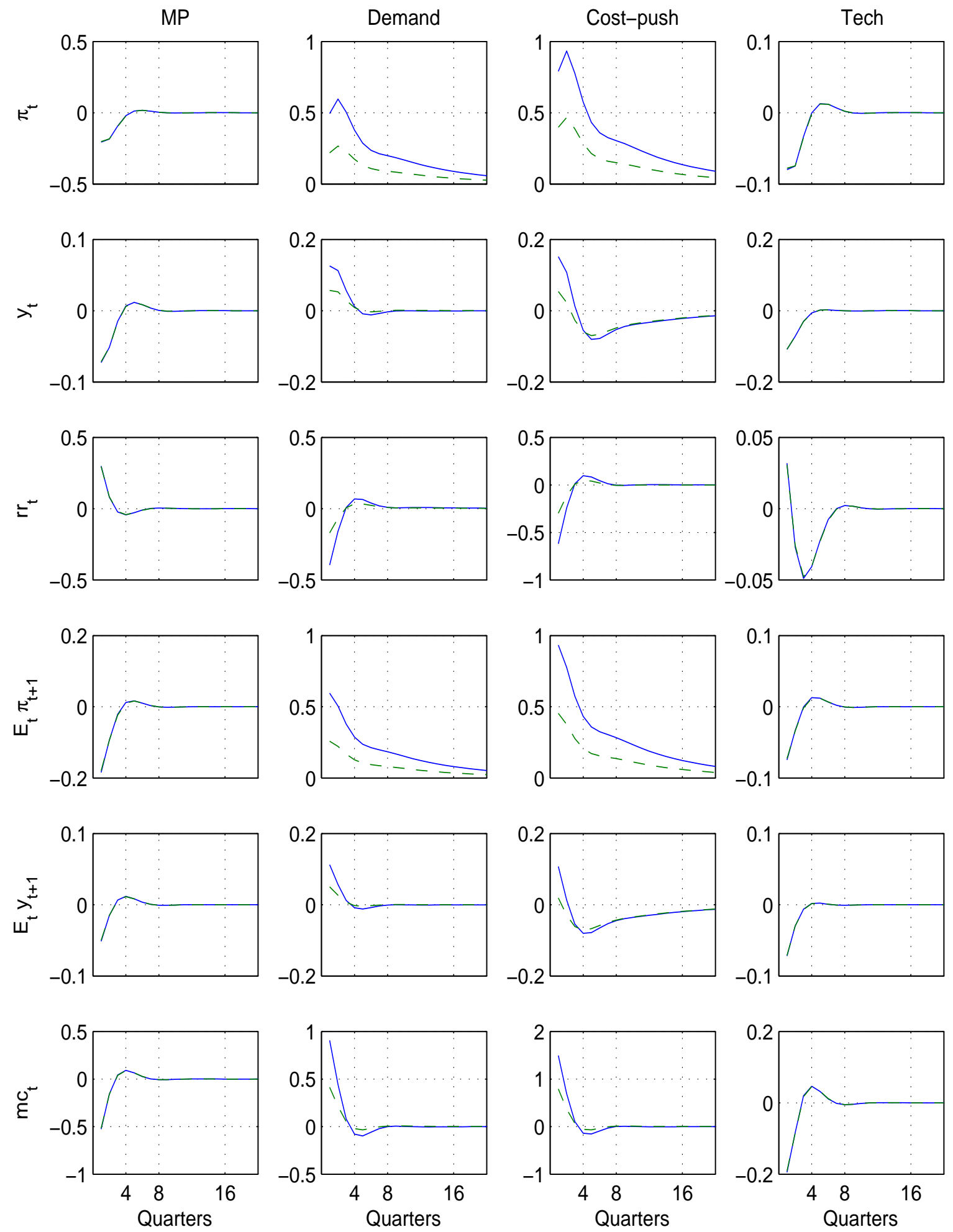

FiguRE 3. Regime switching in policy only (with $\theta_{p}=5$ and $\eta=0.33$ ): impulse responses under the dovish policy regime. The solid line represents the responses from the model that ignores regime shifts in future policy. The dashed line represents the responses from our regimeswitching model. 

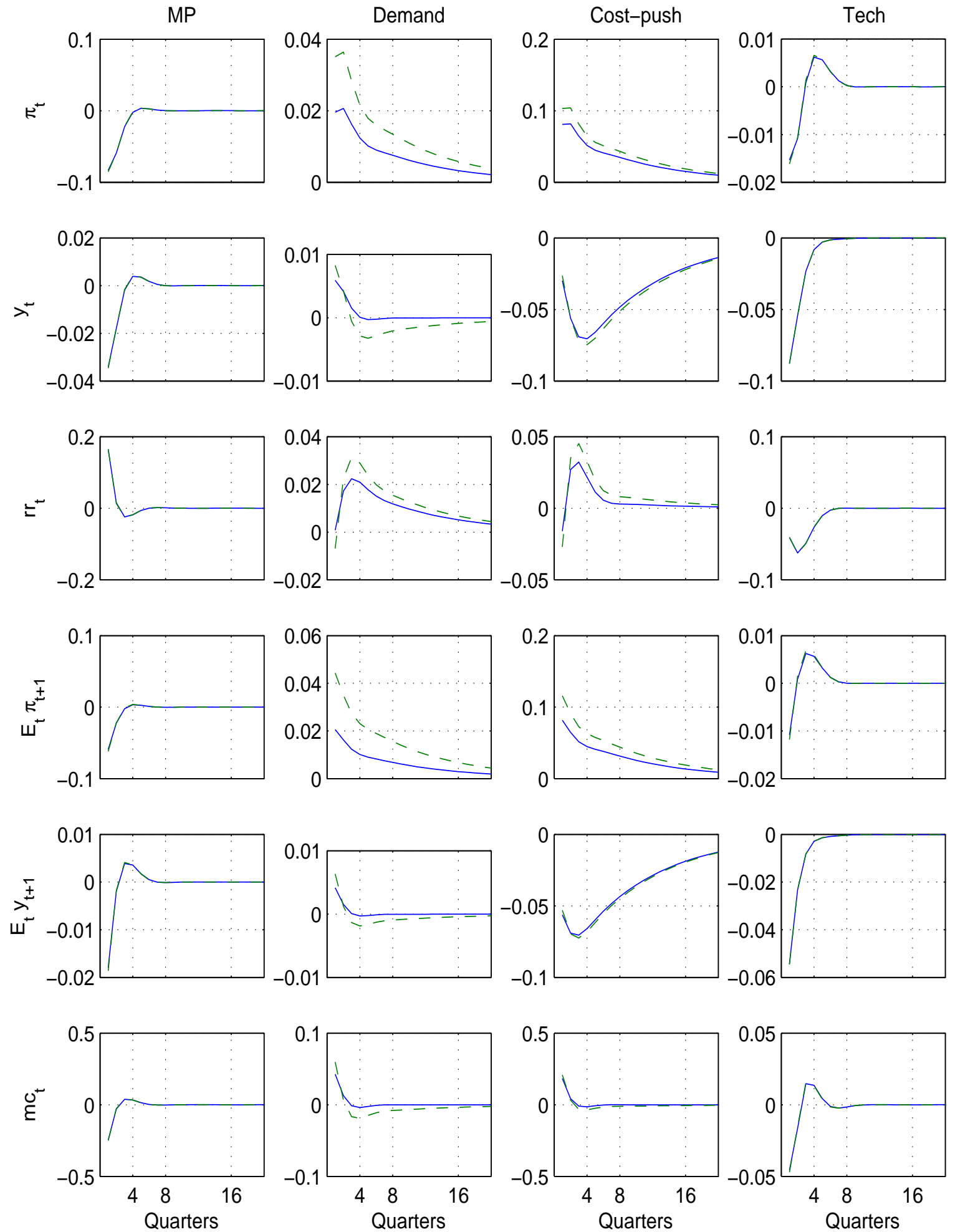

FiguRE 4. Regime switching in policy only (with $\theta_{p}=5$ and $\eta=0.33$ ): impulse responses under the hawkish policy regime. The solid line represents the responses from the model that ignores regime shifts in future policy. The dashed line represents the responses from our regimeswitching model. 

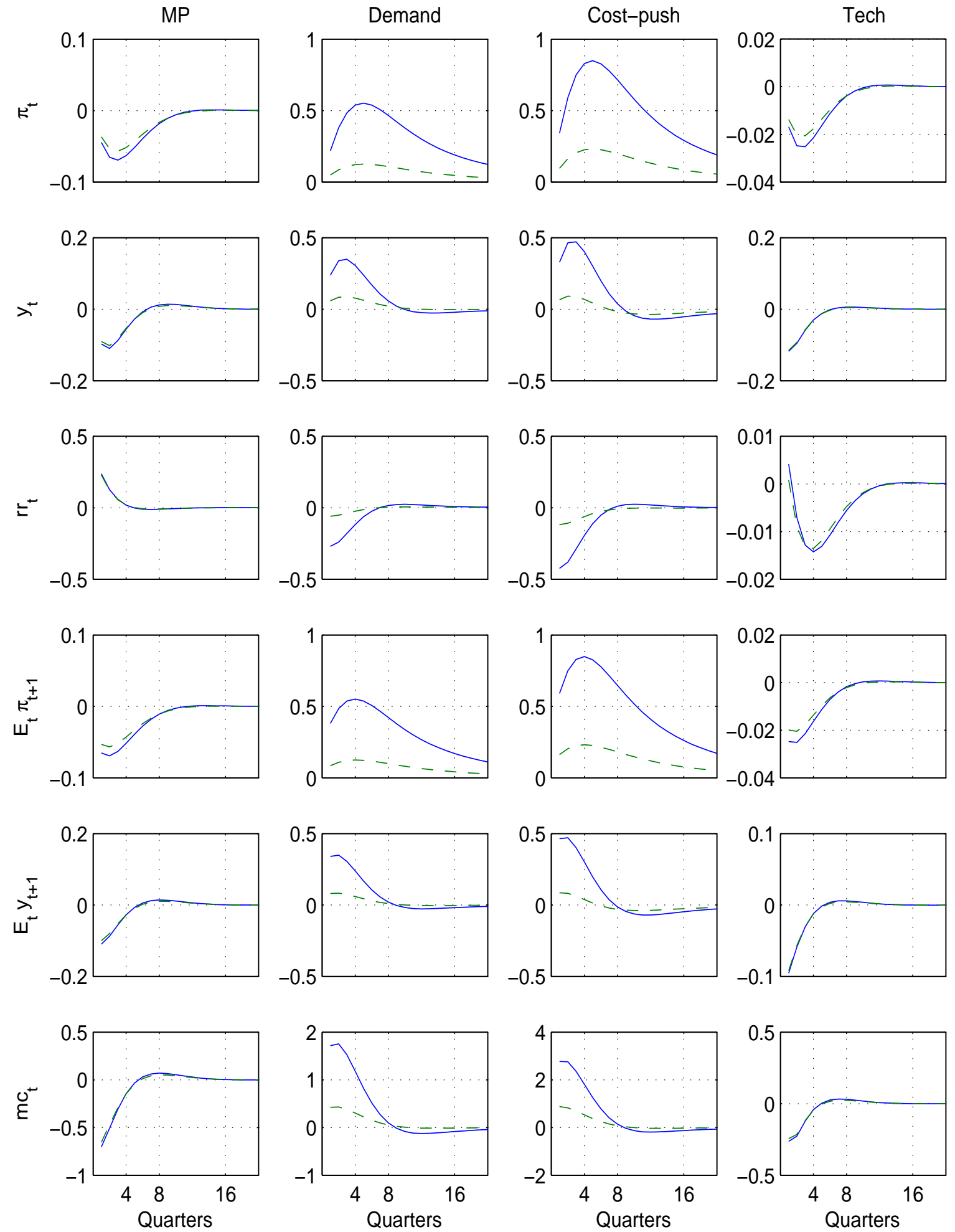

FigURE 5. Regime switching in both policy and firms' behavior: impulse responses under the dovish policy regime. The solid line represents the responses from the model that ignores regime shifts in future policy. The dashed line represents the responses from our regime-switching model. 

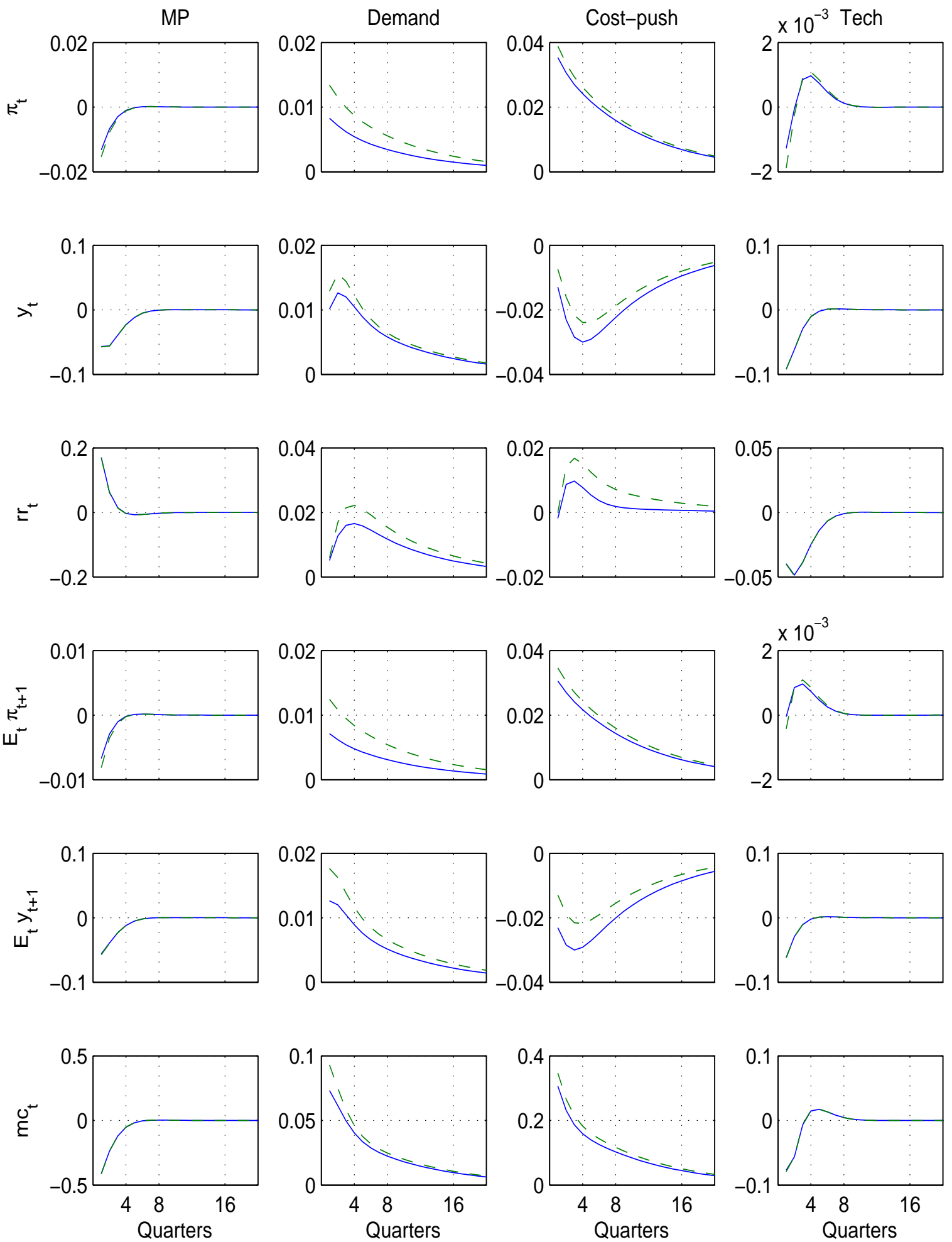

FigURE 6. Regime switching in both policy and firms' behavior: impulse responses under the hawkish policy regime. The solid line represents the responses from the model that ignores regime shifts in future policy. The dashed line represents the responses from our regime-switching model. 

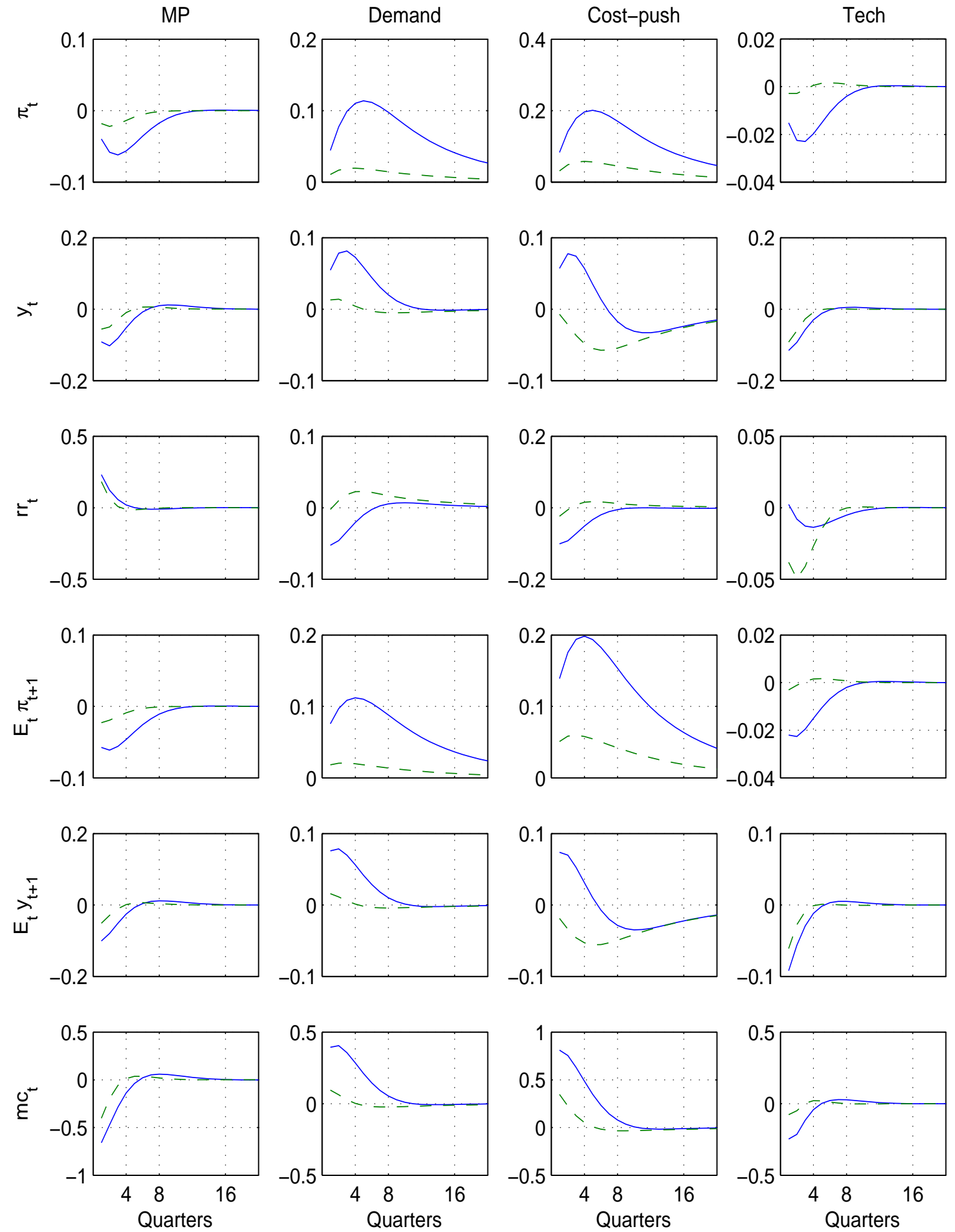

FigURE 7. Impulse responses in the regime-switching model with only policy changing. The solid line represents the responses under the dovish policy regime; the dashed line represents the responses under the hawkish policy regime. 

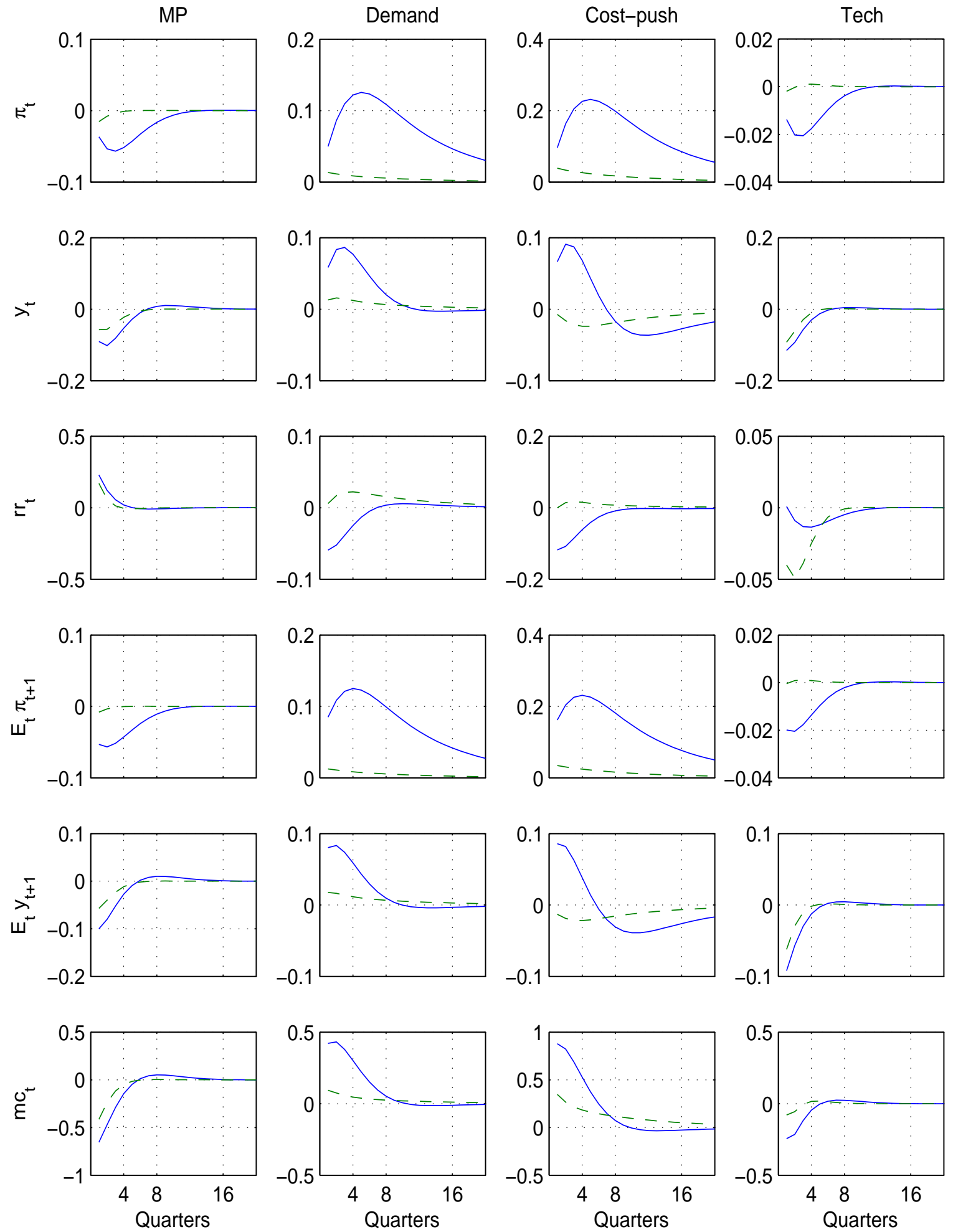

FiguRE 8. Impulse responses in the regime-switching model with changes in both policy regime and firms' behavior. The solid line represents the responses under the dovish policy regime; the dashed line represents the responses under the hawkish policy regime. 


\section{REFERENCES}

Andolfatto, D., And P. Gomme (2003): "Monetary Policy Regimes and Beliefs," International Economic Review, 44(1), 1-30.

Barro, R. J. (1976): "Rational Expectations and the Role of Monetary Policy," Journal of Monetary Economics, 2, 1-32.

(1984): "Discussion on 'Autoregressions, Expectations, and Advice'," American Economic Review, 74(2), 416-417.

Basu, S., And J. G. Fernald (2002): "Aggregate Productivity and Aggregate Technology," European Economic Review, 46(2), 963-991.

Bernanke, B. S. (2004): "The Great Moderation," Speech delivered at the meetings of the Eastern Economic Association, Washington, D.C., February 20.

Bernanke, B. S., And F. S. Mishkin (1997): "Inflation Targeting: A New Framework for Monetary Policy," Journal of Economic Perspectives, 11(2), 97-116.

Bils, M., And P. J. Klenow (2004): "Some Evidence on the Importance of Sticky Prices," Journal of Political Economy, 112(5), 947-985.

Blanchard, O. J., And C. M. Kahn (1980): "The Solution of Linear Difference Methods under Rational Expectations," Econometrica, 48, 1305-1313.

Blanchard, O. J., And J. A. Simon (2001): "The Long and Large Decline in U.S. Output Volatility," Brookings Papers on Economic Activity, 1, 135-164.

Boivin, J., And M. Giannoni (2006): "Has Monetary Policy Become More Effective?," Review of Economics and Statistics, 88(3), 445-462.

Boldrin, M., L. J. Christiano, and J. D. Fisher (2001): "Habit Persistence, Asset Returns, and the Business Cycle," American Economic Review, 91(1), 149166.

Calvo, G. (1983): "Staggered Prices in a Utility-Maximizing Framework," Journal of Monetary Economics, 12(3), 383-398.

Campbell, J. Y., and J. H. Cochrane (1999): "By Force of Habit: A ConsumptionBased Explanation of Aggregate Stock Market Behavior," Journal of Political Economy, 107(2), 205-251.

Cecchetti, S. G., P. Hooper, B. C. Kasman, K. L. Schoenholtz, and M. W. WAtson (2007): "Understanding the Evolving Inflation Process," U.S. Monetary Policy Forum 2007, University of Chicago and Brandeis University.

Chari, V., P. J. Kehoe, and E. R. McGrattan (2000): "Sticky Price Models of the Business Cycle: Can the Contract Multiplier Solve the Persistence Problem?," Econometrica, 68(5), 1151-1180. 
Christiano, L., M. Eichenbaum, and C. Evans (2005): "Nominal Rigidities and the Dynamic Effects of a Shock to Monetary Policy," Journal of Political Economy, $113(1), 1-45$.

Clarida, R., J. Galí, and M. Gertler (2000): "Monetary Policy Rules and Macroeconomic Stability: Evidence and Some Theory," Quarterly Journal of Economics, $115(1)$.

Cogley, T., and T. J. Sargent (2005): "Drifts and Volatilities: Monetary Policies and Outcomes in the Post WWII U.S.," Review of Economic Dynamics, 8(2), 262302.

Cooley, T. F., S. F. LeRoy, and N. Raymon (1984): "Econometric Policy Evaluation: Note," American Economic Review, 74(3), 467-470.

Davig, T., And E. M. Leeper (2007): "Fluctuating Macro Policies and the Fiscal Theory," in NBER Macroeconomic Annual 2006, ed. by D. Acemoglu, K. Rogoff, and M. Woodford. MIT Press, Cambridge, MA.

Del Negro, M., F. Schorfheide, F. Smets, and R. Wouters (2007): "On the Fit and Forecasting Performance of New Keynesian Models," Journal of Business and Economic Statistics, 25(2), 123-143.

Dotsey, M., And R. G. King (2006): "Pricing, Production, and Persistence," Journal of the European Economic Association, 4(5), 893-928.

Eichenbaum, M., And J. D. Fisher (2007): "Estimating the Frequency of Price Reoptimization in Calvo-Style Models," Journal of Monetary Economics, (in press).

Farmer, R. E., D. F. Waggoner, and T. Zha (2006): "Minimal State Variable Solutions to Markov-Switching Rational Expectations Models," Manuscript.

(2007): "Understanding the New-Keynesian Model When Monetary Policy Switches Regimes," NBER Working Paper 12965.

Galí, J., And M. Gertler (1999): "Inflation Dynamics: A Structural Econometric Analysis," Journal of Monetary Economics, 44(2), 195-222.

Gallant, R. A., P. E. Rossi, and G. E. Tauchen (1993): "Nonlinear Dynamic Structures," Econometrica, 61(4), 871Ü-907.

Gambetti, L., E. Pappa, and F. Canova (forthcoming): "The Structural Dynamics of US Output and Inflation: What Explains the Changes?," Journal of Money, Credit, and Banking.

Gertler, M., And J. Leahy (2006): "A Phillips Curve with an Ss Foundation," NBER Working Paper 11971. 
Giannoni, M. P., And M. Woodford (2003): "Optimal Inflation-Targeting Rules," in The Inflation Targeting Debate, ed. by B. S. Bernanke, and M. Woodford, pp. 93-162. University of Chicago Press, Chicago, IL.

Goodfriend, M., And R. G. King (2005): "The Incredible Volcker Disinflation," Journal of Monetary Economics, 52(5), 981-1015.

Hamilton, J. D. (1994): Times Series Analsis. Princeton University Press, Princeton, NJ.

Huang, K., And Z. Liu (2001): "Production Chains and General Equilibrium Aggregate Dynamics," Journal of Monetary Economics, 48(2), 437-462.

(2002): "Staggered Price-Setting, Staggered Wage-Setting, and Business Cycle Persistence," Journal of Monetary Economics, 49(2), 405-433.

IREland, P. N. (2004): "Technology Shocks in the New Keynesian Model," Review of Economics and Statistics, 86(4), 923-936.

King, R. G., And M. W. Watson (1998): "The Solution of Singular Linear Difference Systems Under Rational Expectations," International Economic Review, 39(4), 1015-1026.

Klenow, P. J., And O. Kryvtsov (2005): "State-Dependent or Time-Dependent Pricing: Does It Matter for Recent U.S. Inflation?," NBER Working Paper 11043.

Leeper, E. M., And T. Zha (2003): "Modest Policy Interventions," Journal of Monetary Economics, 50(8), 1673-1700.

Lubik, T. A., And F. Schorfheide (2004): "Testing for Indeterminacy: An Application to U.S. Monetary Policy," American Economic Review, 94(1), 190-219.

LuCAS, R. E. (1972): "Expectations and the Neutrality of Money," Journal of Economic Theory, 4, 103-124.

LuCAS, R. E. (1976): "Econometric Policy Evaluation: A Critique," in CarnegieRochester Conference Series on Public Policy, Vol. 1: The Phillips Curve and Labor Markets, ed. by K. Brunner, and A. Meltzer. North-Holland, Amsterdam, Holland.

McCallum, B. T. (1983): "On Non-Uniqueness in Rational Expectations Models: An Attempt at Perspective," Journal of Monetary Economics, 11(2), 139-168.

Mishkin, F. S. (2004): "Why the Federal Reserve Should Adopt Inflation Targeting," International Finance, 7(1), 117-127.

Muth, J. F. (1961): "Rational Expectations and the Theory of Price Movements," Econometrica, 29, 315-335.

Pencavel, J. H. (1986): "The Labor Supply of Men: A Survey," in Handbook of Labor Economics, ed. by O. C. Ashenfelter, and R. Layard, pp. 3-102. Elsevier, Amsterdam, 
North Holland.

Primiceri, G. (2005): "Time Varying Structural Vector Autoregressions and Monetary Policy," Review of Economic Studies, 72, 821-852.

RotemberG, J. J., And M. Woodford (1997): “An Optimization-Based Econometric Framework for the Evaluation of Monetary Policy," in NBER Macroeconomics Annual, ed. by B. S. Bernanke, and J. J. Rotemberg, pp. 297-346. MIT Press, Cambridge, MA.

Sargent, T. J. (1984): “Auroregressions, Expectations, and Advice," American Economic Review, 74(2), 408-415.

Sargent, T. J., and N. Wallace (1975): "'Rational' Expectations, the Optimal Monetary Instrument, and the Optimal Money Supply Rule," Journal of Political Economy, 83(2), 241-254.

Schorfheide, F. (2005): "Learning and Monetary Policy Shifts," Review of Economic Dynamics, 8(2), 392-419.

Sims, C. A. (1982): "Policy Analysis with Econometric Models," Brookings Papers on Economic Activity, 1, 107-164.

(1987): "A Rational Expectations Framework for Short-Run Policy Analysis," in New Approaches to Monetary Economics, ed. by W. A. Barnett, and K. J. Singleton, pp. 293-308. Cambridge University Press, Cambridge, England.

(2002): "Solving Linear Rational Expectations Models," Computational Economics, 20(1), 1-20.

Sims, C. A., And T. Zha (2006): "Were There Regime Switches in U.S. Monetary Policy?," American Economic Review, 96(1), 54-81.

Stock, J. H., And M. W. Watson (2003): "Has the Business Cycles Changed? Evidence and Explanations," in Monetary Policy and Uncertainty: Adapting to a Changing Economy, pp. 9-56. Federal Reserve Bank of Kansas City, Jackson Hole, Wyoming.

Svensson, L. E., And N. Williams (2005): "Monetary Policy with Model Uncertainty: Distribution Forecast Targeting," Manuscript, Princeton University.

TAYlor, J. B. (1999): "Staggered Price and Wage Setting in Macroeconomics," in Handbook of Macroeconomics, ed. by J. B. Taylor, and M. Woodford, pp. 1009-1050. Elsevier, Amsterdam, North Holland.

Uhlig, H. (1999): "A Toolkit for Analyzing Nonlinear Dynamic Stochastic Models Easily," in Computational Methods for the Study of Dynamic Economies, ed. by R. Marimon, and A. Scott, pp. 30-61. Oxford University Press, Oxford, England. 
Woodford, M. (2003): Interest and Prices: Foundations of a Theory of Monetary Policy. Princeton University Press, Princeton, NJ.

Emory University, Federal Reserve Bank of Atlanta, Federal Reserve Bank of AtLanta 